\title{
Occurrence and origin of mono-, di-, and trimethylalkanes in modern and Holocene cyanobacterial mats from Abu Dhabi, United Arab Emirates
}

\author{
Fabien Kenig, ${ }^{1,2, *}$ J JaP S. Sinninghe Damsté, ${ }^{2.3}$ A. C. Kock-Van Dalen, ${ }^{4}$ \\ W. Irene C. Rupstra, ${ }^{2}$ Alain Y. Huc, ${ }^{1}$ and JAN W. DE LeEUW ${ }^{2}$ \\ 'Institut Français du Pétrole, B.P. 311, F-92506 Rueil Malmaison Cedex, France \\ ${ }^{2}$ Netherlands Institute for Sea Research (NIOZ), Division of Marine Biogeochemistry, \\ P.O. Box 59, 1790 AB Den Burg, Texel, The Netherlands \\ ${ }^{3}$ Department of Geochemistry, Institute of Earth Sciences, Utrecht University, 3508 TA Utrecht, The Netherlands \\ ${ }^{4}$ Organic Geochemistry Unit, Delft University of Technology, de Vries van Heystplantsoen 2, 2628 RZ Delft, The Netherlands
}

(Received November 10, 1994, accepted in revised form April 17, 1995)

\begin{abstract}
Alkanes, highly branched isoprenoids, monomethylalkanes (MMAs), dimethylalkanes (DMAs), and trimethylalkanes (TMAs) are the most abundant components in the hydrocarbon fractions of extracts of four modern and two Holocene cyanobacterial mats $(\sim 1500$ and $5110 \pm 170$ y BP $)$ collected in Abu Dhabi (United Arab Emirates). The homologous families of MMAs, DMAs, and TMAs were identified by comparison of mass spectral and relative retention time data with published data. DMAs were also identified by synthesis of authentic standards, 3,9-dimethyltricosane, 5,9-dimethyltricosane, and 11,15dimethylheptacosane. MMAs, DMAs, and TMAs of the cyanobacterial mats can be separated into two groups on the basis of their distribution patterns and structures. MMAs and DMAs in the $C_{16}-C_{22}$ range are characterized by methyl substituents mainly located at C-6 (or $\omega 6)$ and C-7 (or $\omega 7$ ) and are derived from cyanobacteria. They are relatively abundant components in the modern cyanobacterial mats, but with increasing age of the mats they become much less abundant. On the contrary MMAs, DMAs, and TMAs in the $C_{24}-C_{45}$ range are exclusively found in the Holocene cyanobacterial mats. Their longest chains mainly contain an odd number of carbon atoms and they always carry the methyl substituents at odd numbered carbon atoms. The similarity in composition of this very specific group of branched alkanes with that encountered in insect epicuticular waxes suggests that these sedimentary hydrocarbons originate from insects, which probably grazed on the cyanobacterial mats.
\end{abstract}

\section{INTRODUCTION}

Monomethylalkanes (MMAs) and dimethylalkanes (DMAs) have a long geological history as they have been identified in sediments and crude oils ranging in age from modern (De Leeuw et al., 1985; Robinson and Eglinton, 1990; Shiea et al., 1990, and references therein; Kenig et al., 1990) to Precambrian (Hoering, 1976, 1981; Jackson et al., 1986; Klomp, 1986; Fowler and Douglas, 1987; Summons, 1987; Summons et al., 1988a,b). Although MMAs and DMAs are found in many sediments and crude oils their biological origin is still a matter of investigation and debate (e.g., Summons et al., 1988b; Shiea et al., 1990, 1991; Robinson and Eglinton, 1990). MMAs with mid-chain methylation were proposed by Hoering ( 1981) as products of long-term equilibration of isoand anteiso-alkanes, and were proposed by Kissin (1987) as acid-catalyzed byproducts of alkenes formed during thermal cracking of organic matter. These two hypotheses do not involve specific organisms as a source and suggest that these compounds do not have biomarker value. Two other hypotheses are reported in the literature; MMAs represent direct biological contributions (Fowler and Douglas, 1987) or are diagenetic products derived from biosynthesized functionalized lipid precursors (Summons, 1987; Summons et al., 1988b), both suggesting that MMAs and DMAs can be considered as potential biomarkers.

\footnotetext{
* Present address: Department of Geology and Geophysics, University of Hawaii, 2525 Correa Road, Honolulu, HI 96822, USA.
}

After the discovery of MMAs in cultures of cyanobacteria (Han et al., 1968; Gelpi et al., 1970; Han and Calvin, 1970; Fehler and Light, 1970), these organisms were considered as possible sources of methyl-branched alkanes found in sediments and crude oils. However, a large discrepancy exists between the carbon range $\left(\mathrm{C}_{15}-\mathrm{C}_{21}\right)$ of the MMAs and DMAs identified in living and recent cyanobacterial assemblages and the carbon range $\left(\mathrm{C}_{15}-\mathrm{C}_{33}\right)$ of MMAs and DMAs tentatively identified in ancient sediments and oils. This difference in carbon number distribution compromises correlation of MMAs and DMAs identified in organisms or modem sediments to those in ancient settings and suggests that organisms other than cyanobacteria must be able to synthesize these components or their precursors.

Organisms other than cyanobacteria are known to biosynthesize MMAs and DMAs (e.g., Kolattukudy, 1976; Nelson, 1978). An extensive literature covers the analyses of branched hydrocarbons of insects in which trimethylalkanes (TMA), more than 200 different DMAs and numerous isomers of MMAs were found (e.g., Jackson and Blomquist, 1976; Nelson, 1978; Blomquist et al., 1987; Nelson and Blomquist, 1995).

In this paper we report on the occurrence of suites of specific short-chain $\left(\mathrm{C}_{17}-\mathrm{C}_{21}\right)$ and long-chain $\left(\mathrm{C}_{24}-\mathrm{C}_{41}\right) \mathrm{MMAs}$, DMAs, and TMAs in recent and Holocene sedimentary organic matter. In order to define the biomarker potential of these compounds, we discuss the origin of MMAs, DMAs, and TMAs in recent and ancient sediments, through comparison of their distributions and structures in recent and Holo- 
cene cyanobacterial mats from Abu Dhabi (United Arab Emirates), and through a comparison of their occurrence in living organisms, such as cyanobacteria and insects, and in recent and ancient sediments and crude oils.

\section{GEOLOGICAL SETTING}

Abu Dhabi is located in the southem part of the Arabian Gulf in an area where $90 \%$ of the recent sediments are carbonates (Purser, 1983). A Holocene sea level rise associated with rapid sedimentation reached the Abu Dhabi region 8000 y $\mathrm{BP}$ and a relative regression began 4000-5000 years ago (Evans et al., 1969; Kenig et al., 1990). This relative regression is probably active today and, associated with lateral accretion, resulted in the formation of a wide hypersaline coastal plain, the sabkha, and in the progressive landward aggradation of off-shore islands. The coastal morphology evolved during the Holocene transgression and regression and a number of lagoons resulted. The upper intertidal zone along the landward side of each of these lagoons is the favourable site for the extensive development of microbial mats also referred to as "cyanobacterial mats" and "algal mats" (Burne and Moore, 1987). They form an "algal belt" (Kendall and Skipwith, 1968) along the periphery of the lagoon that may be followed laterally without interruption for a distance of approximately twenty kilometres (Kenig et al., 1990). The width of this belt can reach $2 \mathrm{~km}$. The microbial mat is formed essentially by cyanobacteria, mainly Microcoleus chthonoplastes and Lyngbya aestuarii, which overlay two laminae of bacteria, filamentous bacteria ( salmon pink) and purple sulphur bacteria (purple pink) (Kinsmann and Park, 1976; Cardoso et al., 1978). These organisms form a massive organic fabric. Periodic events, such as storms or very high tides, result in the covering of this organic film by carbonate detrital sediments which, in turn, are recolonized by cyanobacteria and other bacteria. This repetitive process ultimately results in the stacking of organic carbon-rich layers interlaminated with detrital layers, which can reach a thickness of $40 \mathrm{~cm}$. When cyanobacterial mats are distant from the lagoon, hydrodynamics are insufficient to supply carbonate sediments. The size of mineral laminae decreases, resulting in an increase of the total organic carbon (TOC) content of the cyanobacterial mat. However, increasing distance to the lagoon is associated with increasing salinity and gypsum precipitation on the surface of the mat can form the inorganic laminae, and evaporites dominate the mat section (Kenig, 1991). The type of cyanobacterial mat considered in this study represents only $30-60 \%$ of the total belt. This mat has been referred to as the "smooth mat" by Kinsmann and Park (1976) and as the "polygon mat" by Kendall and Skipwith (1968) The remaining 40-70\% of the "algal belt" is comprised of cyanobacterial films which are only few millimetres thick and are unlikely to be preserved in the sedimentary record (Park, 1977; Kenig, 1991).

Both transgressive and regressive sequences are recorded in the sabkha, and all contain cyanobacterial mats in their intertidal sediments (Kenig et al., 1990). The presence of cyanobacterial mats in the modem environment and in both buried sequences offered the opportunity to follow the evolution of its organic geochemical features during early burial.

\section{EXPERIMENTAL}

\subsection{Sampling}

Four samples of modern cyanobacterial mats were collected in a modern tidal channel of a lateral depression associated with the major channel joining the southwestern part of the main lagoon of Abu Dhabi to the Arabian gulf. These cyanobacterial mats were sampled along this tidal channel in environments of different salinities and are thus mineralogically different. At the mouth of the tidal channel (sample 73280; 7.2\% TOC), aragonite, in the form of pelletized needles, was the dominant mineral. The salinity of interstitial waters (SIW) of this cyanobacterial mat is $116 \mathrm{~g} / \mathrm{L}$. Samples $73282(8.0 \%$ TOC; SIW $=142 \mathrm{~g} / \mathrm{L})$ and $73180(4.6 \%$ TOC; SIW $=204 \mathrm{~g} / \mathrm{L})$ were collected $400 \mathrm{~m}$ and $1400 \mathrm{~m}$, respectively, from the mouth of the tidal channel and contain less aragonite. Some gypsum was detected in sample 73180 . The gypsum content progressively increased towards the apex and this mineral forms the bulk of sample 73172 ( $3.2 \%$ TOC; SIW $200 \mathrm{~g} / \mathrm{L}$ ), collected $2000 \mathrm{~m}$ from the mouth of the channel.

The cyanobacterial mat of the regressive sequence ( sample 89705) was collected at a depth of $60 \mathrm{~cm}$ in the sabkha plain, $1.5 \mathrm{~km}$ inland of its modem counterpart. Its TOC content is $2.2 \%$. The estimated age of this mat is 1500 y BP (Kenig, 1991). A physical continuity between the regressive and modern cyanobacterial mats was observed (Kenig, 1991). On the base of its facies, mineralogical assemblage and location within the regressive sabkha sequence, this sample can be considered as a buried equivalent to sample 73180 (Kenig, 1991). The cyanobacterial mat of the transgressive sequence (sample 73061) was collected at a depth of $1.5 \mathrm{~m}$ in the sabkha plain, $7 \mathrm{~km}$ inland from its modern counterpart. The TOC content is $1.7 \%$. Its age is estimated to be older than $5110 \pm 170$ y BP based on the age determination by ${ }^{14} \mathrm{C}$ measurement of overlaying aragonitic shell (Kenig, 1991).

In the field, samples were stored in a cool box and transferred within a few hours to a freezer where they were kept until they could be freeze-dried. Total organic carbon (TOC) content was measured using a Rock-Eval apparatus.

\subsection{Extraction and Separation}

The freeze-dried samples were ground and subsequently extracted with chloroform for $1 \mathrm{~h}$ at $55^{\circ} \mathrm{C}$. The extracts were separated using thin layer chromatography (Merck precoated TLC Silica-Gel 60f254 ) with cyclohexane as a developer. Three fractions were obtained; an immobile polar fraction, an "intermediate" fraction (which contains aromatic and sulphur compounds) and a saturated/unsaturated hydrocarbon fraction. The saturated/unsaturated fraction was further separated using a thin layer chromatography silica gel plate impregnated with a $5 \% \mathrm{AgNO}_{3}$ solution using cyclohexane as a developer. Two fractions, a saturated hydrocarbon and an unsaturated hydrocarbon fraction, were obtained. The branched and cyclic hydrocarbon fractions were isolated from the saturated hydrocarbon fractions using $5 \AA$ molecular sieves.

The saturated branched and cyclic hydrocarbons of the transgressive cyanobacterial mat were also isolated at Texel by Soxhlet extraction (DCM/MeOH, 7:1 (v/v)) followed by column chromatography $\left(\mathrm{Al}_{2} \mathrm{O}_{3}\right.$; hexane), argentation thin layer chromatography ( $\mathrm{SiO}_{2}$, hexane developer), and molecular sieving ( $5 \dot{\mathrm{A}}$ ).

\subsection{Gas Chromatography (GC) and Gas Chromatography- Mass Spectrometry (GC-MS)}

In Rueil Malmaison, GC was carried out on a Varian 2000 instrument equipped with an FIDdetector. The oven temperature was programmed from 50 to $110^{\circ} \mathrm{C}$ at $10^{\circ} \mathrm{C} / \mathrm{min}$ and from 110 to $380^{\circ} \mathrm{C}$ at $3^{\circ} \mathrm{C} / \mathrm{min}$. The column was a CP Sil-5 $(25 \mathrm{~m} \times 0.32 \mathrm{~mm})$ with a film thickness of $0.12 \mu \mathrm{m}$. GC-MS analyses were carried out on a Varian 2000 instrument coupled to a Nermag R $10-10$ quadrupole mass spectrometer, ionization voltage $70 \mathrm{eV}$, mass range of 50 to $650 \mathrm{Da}$, and cycle time of $2 \mathrm{~s}$. Separations were achieved on a JW capillary column $(60 \mathrm{~m} \times 0.32 \mathrm{~mm}$ ) coated with DB] (film thickness $0.25 \mu \mathrm{m}$ ). The GC oven temperature was programmed from 50 to $110^{\circ} \mathrm{C}$ at $10^{\circ} \mathrm{C} / \mathrm{min}$ and then at $3^{\circ} \mathrm{C} / \mathrm{min}$ to $320^{\circ} \mathrm{C}$ at which it was held for 30 min. Mass spectra of dimethylalkane standards and of the trimethylalkanes were obtained at Texel using a Hewlett Packard 5480 gas chromatogram interfaced to a VG-70S mass spectrometer operated at $70 \mathrm{eV}$ with a mass range $40-800 \mathrm{Da}$, cycle time $1.8 \mathrm{~s}$. The gas chromatograph was equipped with a fused silica capilary column ( 25 $\mathrm{m} \times 0.32 \mathrm{~mm}$ ) coated with CP Sil-5 (film thickness $0.2 \mu \mathrm{m}$ ). The oven temperature was programmed from 50 to $130^{\circ} \mathrm{C}$ at $20^{\circ} \mathrm{C} / \mathrm{min}$ and then at $4^{\circ} \mathrm{C} / \mathrm{min}$ to $300^{\circ} \mathrm{C}$ at which it was held for $20 \mathrm{~min}$.

\subsection{Syntheses}

5,9-Dimethyltricosane was prepared by a Grignard reaction of the magnesium salt of 1-bromo-4-methyloctane and hexadecan-2-one followed by dehydration ( $5 \% \mathrm{H}_{2} \mathrm{SO}_{4}$ in tetrahydrofuran, $20^{\circ} \mathrm{C}, 24 \mathrm{~h}$ ) and hydrogenation $\left(\mathrm{PtO}_{2}, 10 \% \mathrm{AcOH}\right.$ in EtOAc). 3,9-Dimethyltricosane and 11,15-dimethylheptacosane were similarly prepared from 
1-bromo-6-methyloctane and hexadecan-2-one and 1-bromo-4-methyltetradecane and tetradecan-2-one, respectively. Hexadecan-2-one and tetradecan-2-one were prepared, respectively, by oxidation of hexadecan-2-ol and tetradecan-2-ol with pyridinium chlorochromate in $\mathrm{CH}_{2} \mathrm{Cl}_{2}$ (Corey and Suggs, 1975), respectively. The appropriate bromides were prepared by a copper halide-catalyzed mono-substitution in 1,5-dibromopentane and 1,3-dibromopropane $(2 \times)$ by the magnesium salts of 2-bromobutane, 2-bromohexane, and 2-bromododecane, respectively (Adringa et al., 1990). 2-Bromododecanc was prepared by reaction of dodecan-2-ol with tertiary phosphine dibromide in dimethylformamide (Wiley et al., 1964).

\section{RESULTS}

Monomethylalkanes (MMAs), dimethylalkanes (DMAs), and to a lesser extent trimethyl-alkanes (TMAs), together with $n$-alkanes, phytane, and highly branched isoprenoid (HBI) hydrocarbons with 20,21, and 22 carbon atoms represent most of the saturated hydrocarbons extracted from both the modern and the Holocene cyanobacterial mats of $\mathrm{Abu}$ Dhabi.

Identification of monomethylalkanes was performed by mass chromatography using the characteristic fragment ions formed by cleavage of the carbon-carbon bond adjacent to the tertiary carbon atoms (Klomp, 1986; Fowler and Douglas, 1987; Summons, 1987). Because these cleavages involve a hydrogen rearrangement (McCarthy et al., 1968; Holzer et al., 1979), even mass fragment ions are characteristic of these compounds and were, therefore, used. Each isomer is characterized by two even mass fragment ions (e.g., 98 and 182 $\mathrm{Da}$ in the case of 6-methyl-heptadecane). Identification was confirmed by comparison of mass spectra of MMAs with those of published authentic standards (Han et al., 1968; Pomonis et al., 1978; Summons, 1987) and by comparison of published retention indices with those measured (Table 1 ).

Identification of DMAs by mass spectrometry is facilitated by their characteristic fragmentation pattems (McCarthy et al., 1968; Pomonis et al., 1980, and references therein). These can be observed in the mass spectra of 6,12-dimethylheptadecane (Fig. 1a). The dominance of the rearrangement ion at $98 \mathrm{Da}\left(\mathrm{C}_{7} \mathrm{H}_{14}\right)$ over the fragment ion at $99 \mathrm{Da}\left(\mathrm{C}_{7} \mathrm{H}_{15}\right)$ formed by simple cleavage (both characteristic fragment ions are due to the cleavage adjacent to a tertiary carbon atom) indicates that this fragment does not carry two methyl substituents (McCarthy et al., 1968) and, thus, that a methyl substituent is located at C-6 of the longest chain. The fragment ion at 197 $\mathrm{Da}$, not associated with an abundant rearrangement ion at 196 $\mathrm{Da}$, indicates that this fragment ion contains (at least) two methyl substituents as the additional methyl substituent has an inhibitory effect on the hydrogen rearrangement (Nelson and Sukkestad, 1975) if separated by less than seven methylene units from the other methyl substituent (Pomonis et al., 1980). The presence of only one major even mass fragment ion and of only one major odd mass fragment ion suggests a symmetry in the methyl substitution. Considering the $\mathrm{m} / \mathrm{z}$ values of these fragments, the methyl substituents are at C- 6 and C-12 $(6, w 6)$. In this mass spectrum (Fig. 1a), the intensities of diagnostic fragment ions are enhanced by the symmetrical character of this compound. A similar fragmentation pattern is observed for the symmetrical 7,11-dimethylheptadecane (7, $\omega 7$; Fig. 1c). Asymmetrical DMAs are characterized by four diagnostic fragment ions, two at even and two at odd mass, as can be observed in the mass spectrum of 6,11-dimethylheptadecane (fragment ions at 98 and $112 \mathrm{Da}$ and 183 and $197 \mathrm{Da}$, respectively; Fig. 1b). However, the fragment ions at 155 and $169 \mathrm{Da}$ corresponding to cleavages internal to methyl groups arc enhanced. A similar fragmentation pattern has already been observed by Pomonis et al. (1980) for other DMAs with methyl substituents also separated by four methylene units. In such a case, tertiary carbocations, more stable than primary carbocations, are formed during fragmentation following the pathway described in Fig. 2. Upon cleavage A (Fig. 2), internal to the methyl group, a six-membered ring proton rearrangement occurs and results in the formation of a more stable fragment ion.

The identifications of DMAs in the $\mathrm{C}_{17}-\mathrm{C}_{20}$ range were confirmed by comparison of the measured retention indices with those calculated following the additivity principle of Kissin et al. (1986; Table 2) and by comparison of their mass spectra and retention times with those published ( De Leeuw et al., 1985; Robinson and Eglinton, 1990; Shiea et al., 1990). The identifications of three homologous series of dimethylalkanes in the $\mathrm{C}_{23}-\mathrm{C}_{41}$ carbon number range were confirmed by mass spectrometry and by coelution on two different capillary columns of synthesized authentic standards (3,9-dimethyltricosane; 5,9-dimethyltricosane; 11,15-dimethylheptacosane; Fig. 3) and of an authentic standard (9,13-dimethylheptacosane). The measured retention indices of DMA homologs were found to be perfectly correlated when plotted against carbon number $\left(r^{2}\right.$ $=0.99$ ) and were in good agreement with those reported in the literature (Table 1 ).

TMAs were identified by comparison of mass spectral data and retention indices with published data and by comparison with the fragmentation patterns of DMAs. Retention indices calculated following the additivity principle of Kissin et al. (1986) on the basis of tentative structures fit the retention indices measured (Table 1).

\subsection{Modern Cyanobacterial Mats}

The bimodal distribution of the saturated hydrocarbons of modern cyanobacterial mats of Abu Dhabi is well exemplified by the chromatogram of sample 73180 (Fig. 4a). The first part is dominated by $n$-heptadecane $\left(n-C_{17}\right)$ and MMAs and DMAs in the range $C_{17}$ to $C_{21}$. The second cluster is dominated by $n$-alkanes, with a maximum at $n-C_{31}$ and a strong odd-over-even carbon number predominance. Small peaks representing isoprenoid hydrocarbons such as squalane (46) and cyclic compounds such as $17 \beta$-trinorhopane (54) and $17 \beta, 21 \beta(\mathrm{H})$-homohopane $(74)$ are observed. A partial gas chromatogram of the compounds present in the nonadduct (Fig. 4b) reveals the dominance of MMAs and DMAs over the few other branched and cyclic compounds such as the $\mathrm{C}_{20} \mathrm{HBI}$ 2,6,10-trimethyl-7-(3-methylbutyl)dodecane ( $\underline{3}$; Yon et al., 1982) and phytane (13). The nonadducts of the saturated hydrocarbon fractions of three other modern cyanobacterial mats, which were formed in environments of different salinities, contain similar suites of MMAs and DMAs (Fig. 5) as sample 73180 (Fig. 4). However, the relative abundances of the various isomers vary from sample to sample. 
Table 1 Compounds identified in the saturated hydrocarbon fractions of modern and holocene microbial mats of Abu Dh: measured $\left(\mathrm{RI}_{\mathrm{m}}\right)$ retention indices and those reported in the literature $\left(\mathrm{Ri}_{1}\right)$ and their occurrence in insect waxes.

\begin{tabular}{|c|c|c|c|c|}
\hline No." & Compound & $\mathrm{RI}_{\mathrm{m}}$ & $\mathrm{RI}_{\mathrm{t}}{ }^{\prime \prime}$ & $\begin{array}{r}\text { reported } \\
\text { wa }\end{array}$ \\
\hline 1 & 8-methylhexadecane & 1643 & & \\
\hline 2 & 5,9-dimethylhexadecane & 1691 & & \\
\hline 3 & 2,6,10-trimethyl-7-(3-methylbutyl)dodecane & 1706 & $1708^{\mathrm{ab}}$ & \\
\hline 4 & 7-methylheptadecane & 1744 & $1743^{c}$ & \\
\hline 5 & 6-methylheptadecane & 1747 & $1746^{\mathrm{C}}$ & \\
\hline 6 & 4-methylheptadecane & 1756 & $1758^{c}$ & \\
\hline 7 & 7,11-dimethylheptadecane & 1785 & & \\
\hline 8 & 6,11-dimethylheptadecane & 1794 & & \\
\hline 9 & 6,12-dimethylheptadecane & 1796 & $1797^{\mathrm{c}}$ & \\
\hline 10 & 2,6,10-trimethyl-7-(3-methylpentyl)dodecane & 1801 & $1803^{2}$ & \\
\hline 11 & 4,12-dimethylheptadecane & 1804 & & \\
\hline 12 & 3,7,11-trimethyl-7-(3-methylbutyl)tridecane & 1806 & & \\
\hline 13 & 2,6,10,14-tetramethylhexadecane (phytane) & 1812 & & \\
\hline 14 & 6,7-dimethylheptadecane & 1815 & & \\
\hline 15 & 5,6-dimethylheptadecane & 1821 & & \\
\hline 16 & 8- and 7-methyloctadecane & 1846 & $1847^{c}$ & \\
\hline 17 & 6-methyloctadecane & 1848 & & \\
\hline 18 & 5-methyloctadecane & 1853 & & \\
\hline 19 & unknown branched compound & 1858 & & \\
\hline 20 & 7,12-dimethyloctadecane & 1887 & & \\
\hline 21 & 6,12-dimethyloctadecane & 1892 & & \\
\hline 22 & 6,13-dimethyloctadecane & 1896 & & \\
\hline 23 & 5,13-dimethyloctadecane & 1899 & & \\
\hline 24 & 3,7,11-trimethyl-6-(3-methylpentyl)tridecane & 1901 & $1903^{\circ}$ & \\
\hline 25 & 6,7-dimethyloctadecane & 1915 & & \\
\hline 26 & 8- and 7-methylnonadecane & 1944 & $1945^{\circ}$ & \\
\hline 27 & 6-methylnonadecane & 1948 & & \\
\hline 28 & 2,6,10,14-tetramethyl-7-(3-methylbutyl)pentadecane & 2105 & $2112^{\mathrm{a}}, 2109^{\mathrm{b}}$ & \\
\hline 29 & unknown component $(\mathrm{m} / \mathrm{z} 83,140,238)$ & 2214 & & \\
\hline 30 & 2,6,10,15,19-pentamethyleicosane (PME) & 2241 & & \\
\hline 31 & 11 - and 9-methyltricosane & 2337 & $2237^{d}, 2235^{c}$ & , \\
\hline 32 & S-methyltricosane & 2346 & $2350^{\circ}$ & , \\
\hline 33 & 3-methyltricosane & 2371 & $2374^{\mathrm{d}}, 2373^{\mathrm{f}}$ & , \\
\hline 34 & 5,x-dimethyltricosane & 2386 & & \\
\hline 35 & 3,9-dimethyltricosane & 2404 & & \\
\hline 36 & 11-methyltetracosane & 2437 & $2435^{d}, 2438^{f}$ & . \\
\hline 37 & 3,7,11-trimethyltricosane & 2460 & $2454^{8}$ & . \\
\hline 38 & 13- and 11-methylpentacosane & 2535 & $2533^{\text {e.ch }}, 2537^{d}, 2536^{i}$ & . \\
\hline 39 & 5-methylpentacosane & 2552 & $2549^{\mathrm{e} . \mathrm{h}}, 2550^{\mathrm{j}}, 2556^{\mathrm{d}}$ & . \\
\hline 40 & 11,15-dimethylpentacosane & 2565 & $2572^{d}, 2557^{e}$ & . \\
\hline 41 & 3-methylpentacosane & 2574 & $2574^{\mathrm{d} h \mathrm{~h}}, 2573^{i k}, 2572^{\mathrm{e}}$ & . \\
\hline 42 & $5, x$-dimethylpentacosane & 2585 & $2583^{i}, 2584^{k}, 2586^{k}$ & . \\
\hline 43 & $3,9-$ and 3,11 -dimethylpentacosane & 2607 & $2610^{i}, 2608^{l}, 2610^{k}$ & r. \\
\hline 44 & 11 - and 10-methylhexacosane & 2636 & $2634^{\prime}, 2632^{1}$ & \\
\hline 45 & $\mathrm{C}_{28} \mathrm{TMA}$ & 2647 & & \\
\hline 46 & $2,6,10,15,19,23$-hexamethyltetracosane (squalane) & 2663 & & \\
\hline 47 & 13- and 11-methylheptacosane & 2733 & $\begin{array}{l}2732^{\mathrm{s}, \mathrm{m}}, 2730^{\mathrm{j}}, \\
2735^{\alpha,}, 2734^{\prime}, 2733^{\mathrm{i}}\end{array}$ & \\
\hline 48 & 5-methylheptacosane & 2744 & $2749^{e}$ & \\
\hline 49 & 11,15- and 9,13-dimethylheptacosane & 2762 & $\begin{array}{l}2765^{\mathrm{h}}, 2760^{\mathrm{i}}, 2758^{\mathrm{d}} \\
2766^{\mathrm{f}}, 2763^{\mathrm{n}}\end{array}$ & \\
\hline 50 & 3-methylheptacosane & 2772 & $\begin{array}{l}2772^{\mathrm{e}, \mathrm{m}}, 2770^{\mathrm{j}}, 2773^{\mathrm{i}} \\
2771^{\mathrm{f}}\end{array}$ & \\
\hline 51 & 5,11-(minor) and 5,13-dimethylheptacosane & 2783 & $2783^{\mathrm{k} \cdot \mathrm{m}}, 2780^{\mathrm{j}}, 2788^{\mathrm{k}}$ & \\
\hline 52 & $17 \alpha-22,29,30$-trinorhopane & 2795 & & \\
\hline 53 & 3,9-dimethylheptacosane & 2808 & $2805^{j}, 2809^{k}, 2806^{\circ}$ & \\
\hline 54 & $17 \beta-22,29,30$-trinorhopane & 2828 & & \\
\hline 55 & $\mathrm{C}_{30}$ TMA & 2837 & & \\
\hline 56 & 13-and 11-methylnonacosane & 2932 & $\begin{array}{l}2932^{\mathrm{m}}, 2927^{\mathrm{p}}, 2930^{\mathrm{j}} \\
2936^{\mathrm{d}}, 2935^{\mathrm{f}}\end{array}$ & \\
\hline 57 & 5-methylnonacosane & 2949 & $2951^{\mathrm{m}}, 2952^{\mathrm{d}}, 2950^{\mathrm{e}}$ & \\
\hline 58 & 11,15- (minor) and 9,13-dimethylnonacosane & 2963 & $\begin{array}{l}2962^{\mathrm{k} m}, 2965^{\mathrm{j}}, 2963^{\mathrm{d}} \\
2960^{\mathrm{d}}, 2961^{\mathrm{n}}\end{array}$ & \\
\hline
\end{tabular}


Table 1. (Continued)

\begin{tabular}{|c|c|c|c|c|}
\hline No: & Compound & $\mathbf{R I}_{\mathbf{m}}$ & $\mathbf{R I}_{\mathbf{t}}^{\prime \prime}$ & $\begin{array}{l}\text { reported in insect } \\
\text { waxes }\end{array}$ \\
\hline 59 & 3-methylnonacosane & 2973 & $\begin{array}{l}2972^{\mathrm{e}, \mathrm{Lm}}, 2970^{\prime} \\
2973^{\mathrm{df}}\end{array}$ & $\sqrt{ }$ \\
\hline 60 & 5,9- and 5,11-dimethylnonacosane and $17 \beta, 2 \mathrm{l} \alpha(\mathrm{H})$-norhopane & 2983 & $2985^{j}$ & $\sqrt{ }$ \\
\hline 61 & 3,9-dimethylnonacosane & 3007 & $3008^{\mathrm{m}}, 3006^{\mathrm{d}}$ & $\sqrt{ }$ \\
\hline 62 & $17 \alpha, 21 \beta(H)-30$-norhopane & 3021 & & \\
\hline 63 & 3,9,13-trimethylnonacosane & 3037 & & \\
\hline 64 & $17 \beta, 21 \beta(H)-30$-norhopane & 3045 & & \\
\hline 65 & $17 \beta, 21 \alpha(H)$-hopane & 3058 & & \\
\hline 66 & 2-methyltriacontane & 3084 & & \\
\hline 67 & 15-, 13- and 11-methylheneitriacontane & 3131 & $\begin{array}{l}3126^{\mathrm{p}}, 3130^{\mathrm{de}, \mathrm{f}}, \\
3133^{\mathrm{kqq}}\end{array}$ & $\sqrt{ }$ \\
\hline 68 & $17 \beta, 21 \beta(\mathrm{H})$-hopane & 3150 & & \\
\hline 69 & $11,15-$ and 9,13-dimethylheneitriacontane & 3162 & $\begin{array}{l}3158^{\mathrm{d}}, 3160^{\mathrm{q}}, 3161^{1} \\
3164^{\mathrm{n}}\end{array}$ & $\sqrt{ }$ \\
\hline 70 & 3-methylheneitriacontane & 3172 & $\begin{array}{l}3175^{\mathrm{d}}, 3168^{1}, 3176^{\mathrm{f}}, \\
3172^{\mathrm{e}}\end{array}$ & $\sqrt{ }$ \\
\hline 71 & 5,9-dimethyheneitriacontane & 3181 & & $\sqrt{ }$ \\
\hline 72 & 3,9-dimethylheneitriacontane & 3207 & $3206^{\circ}$ & $\sqrt{ }$ \\
\hline 73 & $3,9,15$ - and $3,11,15$-trimethylhentriacontane & 3231 & $3237^{8}$ & \\
\hline 74 & $17 \beta, 21 \beta(H)$-homohopane & 3270 & & \\
\hline 75 & $17-, 15,-$ and $13-$ methyltritriacontane & 3331 & $\begin{array}{l}3332^{p}, 3330^{d f} \\
3333^{2 q}, 3334^{n}\end{array}$ & $\sqrt{ }$ \\
\hline 76 & 13,17- and 11,15-dimethyltritriacontane & 3363 & $3360^{d}, 3359^{q}, 3357^{c}$ & $\sqrt{ }$ \\
\hline 77 & 3-methyltritriacontane & 3374 & $3375^{\mathrm{d}}$ & $\sqrt{ }$ \\
\hline 78 & 3,9-dimethyltritriacontane & 3406 & $3406^{\circ}$ & $\sqrt{ }$ \\
\hline 79 & 3,7,11-trimethyltritriacontane & 3436 & $3439^{8}$ & \\
\hline 80 & $2,6,10,14,19,23,27,31$-octamethyldotriacontane (lycopane) & 3502 & & \\
\hline 81 & $17-, 15-$ and $13-$ methylpentatriacontane & 3529 & $3531^{\text {n.p. }}, 3530^{\mathrm{d}, \mathrm{f}}, 3527^{\mathrm{i}}$ & $\sqrt{ }$ \\
\hline 82 & 13,17- and 11,15-methylpentatriacontane & 3560 & $3555^{\mathrm{di}}, 3553^{\mathrm{i}}, 3560^{\mathrm{knn}}$ & $\sqrt{ }$ \\
\hline 83 & 19-, 17-, 15- and 13-methyiheptatriacontane & 3730 & $3730^{n}$ & $\sqrt{ }$ \\
\hline 84 & 15,19-, 13,17-and 11,15-dimethylheptatriacontane & 3758 & $3752^{h}, 3751^{k n n}$ & $\sqrt{ }$ \\
\hline 85 & centrally branched methylnonatriacontanc & 3927 & $3930^{n}$ & $\sqrt{ }$ \\
\hline 86 & centrally branched dimethylnonatriacontane & 3957 & $3960^{n}$ & $\checkmark$ \\
\hline \multicolumn{5}{|c|}{ 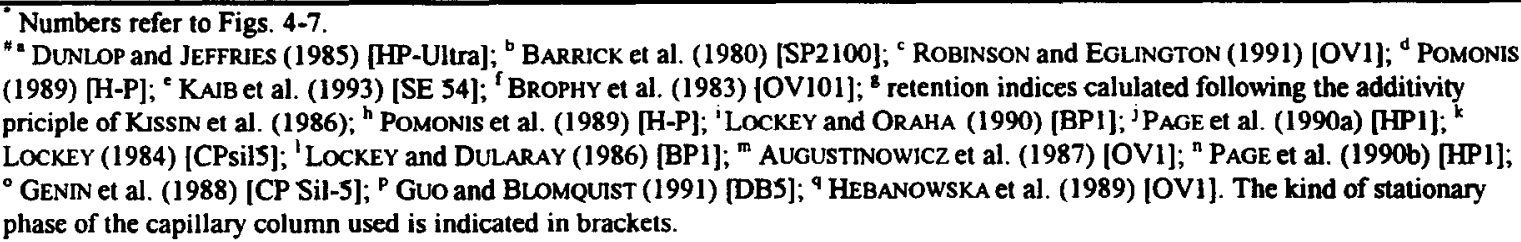 } \\
\hline
\end{tabular}

\subsubsection{Distribution of short-chain MMAs}

The MMAs occur in the $\mathrm{C}_{17}-\mathrm{C}_{20}$ range in the modern cyanobacterial mats. With the exception of the methylhexadecanes (1), which are dominated by the 8-methyl isomer, the methylheptadecanes $(4,5)$, methyloctadecanes $(16,17)$ and methylnonadecanes $(26,27)$ are dominated by the $6-$ and 7 methyl isomers. In the latter three cases only a minor contribution of the 8-methyl isomers (which coelute with the 7 methyl isomers) was apparent. Isomers with the methyl group located at $\mathrm{C}-5(\underline{18})$ and $\mathrm{C}-4(\underline{6})$ are present in lower amounts (Figs. 4b, 5). Mass chromatography also indicated the presence of traces of all other isomers. Only the 7-and 8-methylheptadecanes have been previously reported in Abu Dhabi cyanobacterial mats (Cardoso et al., 1978; Gibbons, 1978).

\subsubsection{Distribution of short-chain DMAs}

The DMAs occur in the $\mathrm{C}_{18}-\mathrm{C}_{21}$ range in the modern cyanobacterial mats (Fig. 4, Tables 1,2 ). The two major peaks in the gas chromatogram of the nonadduct of the saturated hydrocarbon fraction of sample 73180 (Fig. 4) correspond to DMAs with nineteen and twenty carbon atoms (6,12-dimethylheptadecane (9) and 6,12-dimethyloctadecane (21), respectively). Numerous other isomers of DMAs were identified in these cyanobacterial mats (Table 2 ). The DMAs can be divided in two groups. The first group has a minimum of three methylene units between the methyl substituents. It dominates, in number of isomers and in relative abundance, the second group that carries methyl substituents on adjacent carbon atoms $(14,15,25$, Figs. $4 \mathrm{~b}, 5$, Table 2). With the exception of three DMAs present in low concentrations or as trace components (5,9-dimethylhexadecane $(5, \omega 8),(2) ; 4,12$-dimethylheptadecane $(4, \omega 6),(11) ; 7,11$-dimethyloctadecane $(7, \omega 8))$, all DMAs possess methyl substituents at C-5 (or $\omega 5$ ), C-6 (or $\omega 6$ ), and C-7 (or $\omega 7$ ) only (Table 2 ). In particular, the most abundant DMAs $(\underline{8}, 9,21,22$; Figs. $4 \mathrm{~b}, 5)$ all have methyl groups at C-6 (or $\omega 6)$ and $C-7$ (or $\omega 7)$. This sug- 
(a)

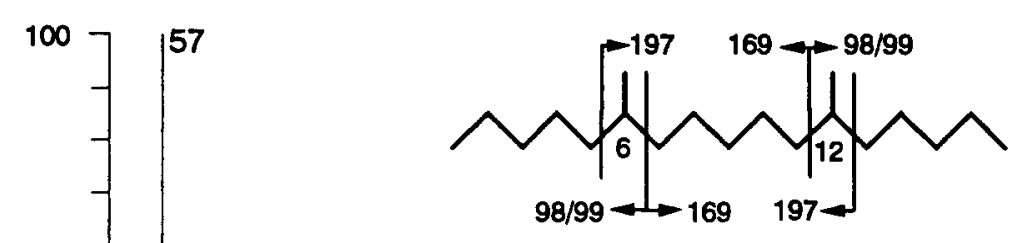

(b)

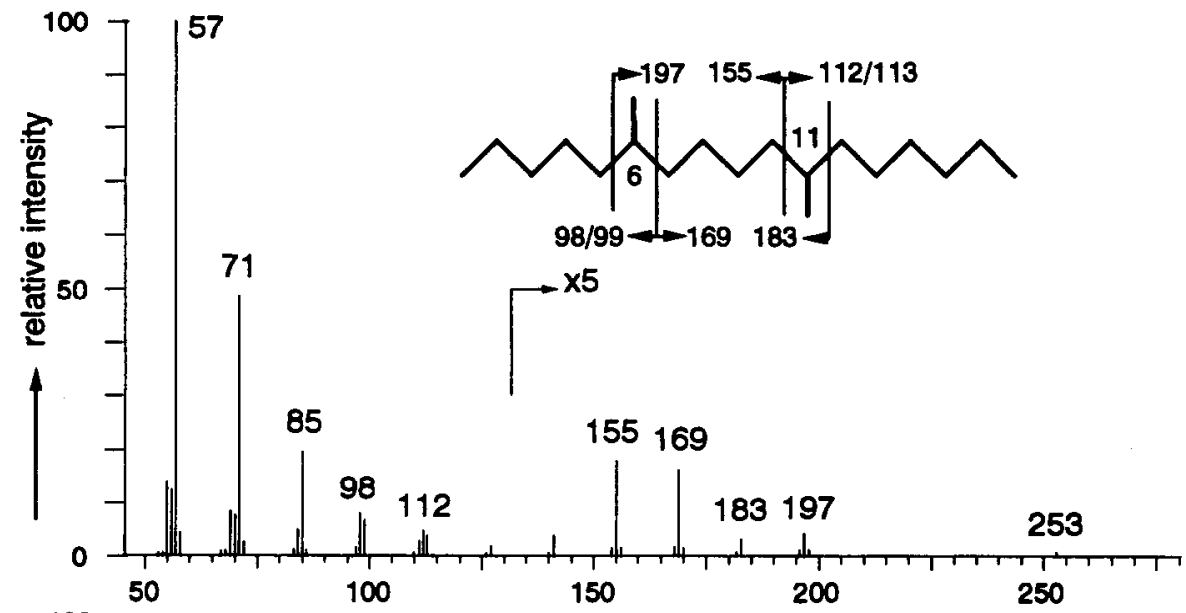

(c)

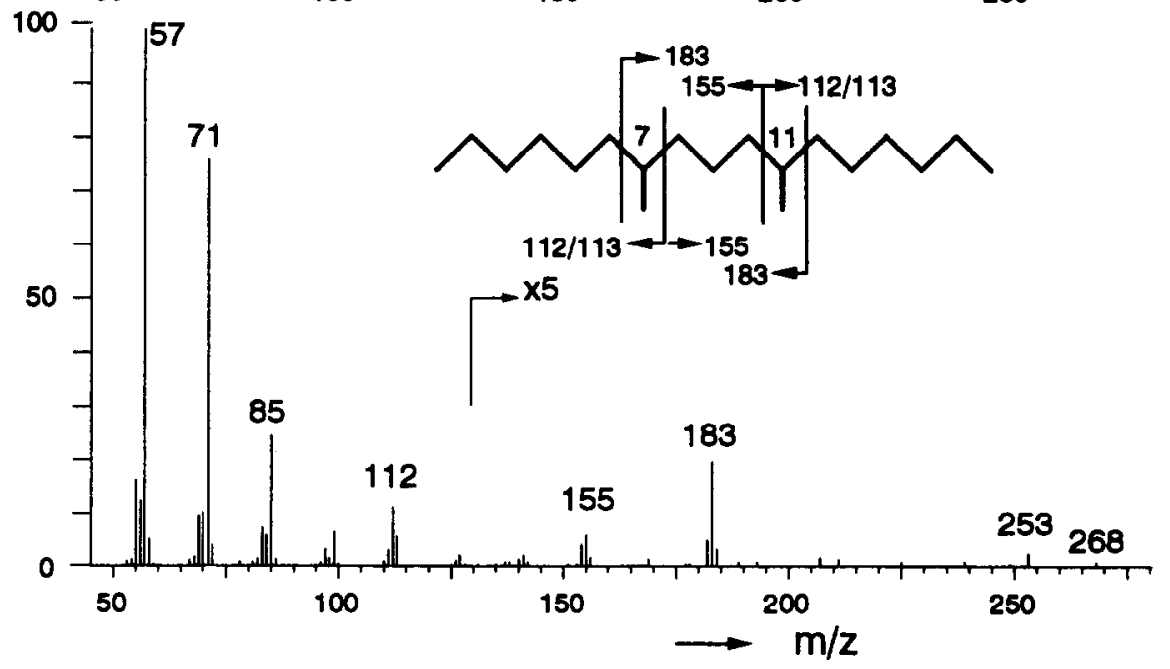

FIG. 1. Mass spectra, subtracted for background, of components tentatively identified as (a) 6,12-dimethylheptadecane (9), (b) 6,11-dimethylheptadecane ()), and (c) 7,11-dimethylheptadecane ().

gests a common biosynthetic pathway for all DMAs. It should be noted, however, that methylation at C-6 and C7 is also a common feature of the most abundant $\mathrm{C}_{19}-\mathrm{C}_{21}$ MMAs, even though 8-methylalkanes also occur. This may suggest a common biosynthetic pathway for MMAs and DMAs in this range.

\subsection{Regressive Cyanobacterial Mat}

The distribution of the saturated hydrocarbons in the regressive cyanobacterial mat is also bimodal (Fig. 6) but is rather different from that in the modem cyanobacterial mats (Figs. 4, 5). The first cluster of components is also composed 

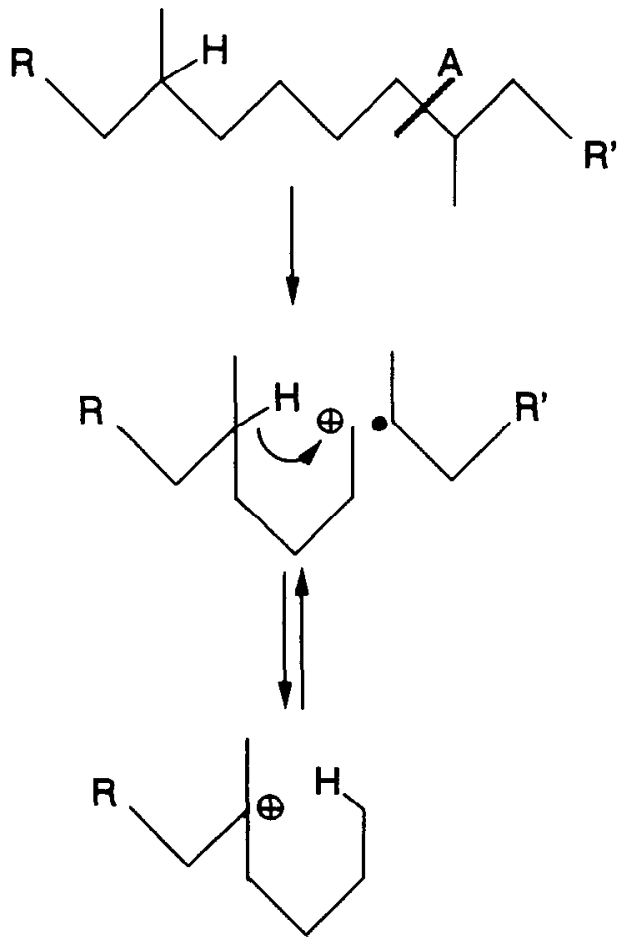

FIG. 2. Scheme of a tertiary carbocation formation by a six-membered ring proton rearrangement following electron impact. (A) of a branched compound with methyl groups separated by four methylene units.

of molecules eluting between $n-\mathrm{C}_{16}$ and $n-\mathrm{C}_{22}$ but the dominant compounds are the $\mathrm{C}_{20} \mathrm{HBI}$ (3) and phytane (13). The $C_{21}$ and $C_{22}$ HBIs (2,6,10-trimethyl-7-(3-methylpentyl)dodecane (10) and 3,7,11-trimethyl-6-(3-methylpentyl) tridecane (24), respectively)) were tentatively identified by comparison of their mass spectra with those previously published (Dunlop and Jefferies, 1985). The other differences between the modern mats and the regressive mat are the lower relative intensities of $\mathrm{C}_{17}-\mathrm{C}_{20} n$-alkanes and short-chain MMAs and DMAs in the regressive mat. However, the shortchain MMAs and DMAs have similar carbon number and isomer distributions as those in the modern cyanobacterial mats.

The second cluster of compounds (Fig. 6) is dominated by $n$-alkanes with a strong odd-over-even carbon number predominance maximizing at $n-C_{29}$ and $n-C_{31}$. A major difference with the modern cyanobacterial mats is the presence of long-chain MMAs (31, 38, 47, 56, 67; Fig. 6) and DMAs (43, 53; Fig. 6 ) in the range $\bar{C}_{24}$ to $C_{37}$. The distributions of long-chain MMAs, DMAs and TMAs are identical in the regressive and transgressive cyanobacterial mats (cf. Figs. 6, 7 ). Since their relative abundances are higher in the transgressive cyanobacterial mat, their detailed molecular structures and distributions are discussed in the following paragraphs.

\subsection{Transgressive Cyanobacterial Mat}

The gas chromatogram of the saturated hydrocarbon fraction of the transgressive mat also reveals a bimodal distribu- tion (Fig. 7). The compounds dominating the first cluster are the $C_{20}, C_{21}$, and $C_{22}$ HBIs $(3,10,24)$ and phytane (13). The $n$-alkanes in this cluster are dominated by $n-C_{17}$. The shortchain MMAs and DMAs, which were major compounds of the first cluster in the modern and regressive cyanobacterial mats, are absent or present in trace amounts only. The presence of minor amounts of tentatively identified 3,7,11-trimethyl-6-(3-methylbutyl) tridecane (12), a second isomer of the $\mathrm{C}_{21} \mathrm{HBI}$ should be noted. The mass spectrum of this compound is reported by Kenig (1991).

The second cluster is dominated by $n$-alkanes with a strong odd-over-even carbon number predominance maximizing at $n-\mathrm{C}_{29}$ and $n-\mathrm{C}_{31}$ (Fig. 7), by isomers of long-chain MMAs, and by unresolved mixtures of 3, $x$-DMAs, $5, x$ DMAs, centrally branched DMAs and TMAs with carbon numbers ranging from $C_{24}$ to $C_{41}$ (Fig. 7a, c). A number of pentacyclic compounds, such as $17 \beta$-trinorhopane ( $\underline{54}$ ), $17 \beta, 21 \beta(\mathrm{H})$-homohopane ( 74$)$, and isoprenoid compounds such as 2,6,10,14,-tetramethyl-7-(3-methylbutyl)pentadecane $\left(\mathrm{C}_{25} \mathrm{HBI}, \underline{28}\right), 2,6,10,15,19$-pentamethyleicosane (PME, 30), squalane (46), and 2,6,10,14,19,23,27,31-octamethyldotriacontane (Jycopane, $\underline{80}$ ) were also identified (Fig. 7c; Table 1 ).

\subsubsection{Distribution of long-chain MMAs}

The MMAs represented by discrete peaks in the chromatogram of the nonadduct of the hydrocarbon fraction of the transgressive cyanobacterial mat (Fig. 7c) are listed in Table 1. Three homolugous series of compounds are present: 3 methylalkanes in the range $C_{24}-C_{34}(33,41,50,59,70,77)$, 5-methylalkanes in the $\mathrm{C}_{24}-\mathrm{C}_{30}$ range $(32,39,48,57)$, and mid-chain methylalkanes in the $\mathrm{C}_{24}-\mathrm{C}_{40}$ range $(\underline{31}, 38,44$, $\underline{47}, \underline{56}, \underline{67}, \underline{75}, \underline{81}, \underline{83}, \underline{85})$. This latter series of peaks is com-

Table 2. Measured retention indices ( $\mathrm{RI}_{\mathbf{2}}$ ) and theoretical retention indices (RI) of short-chain DMA's tentatively identified in the saturated hydrocarton fractions of recent microbial mats of Abu Dhabi.

\begin{tabular}{|c|c|c|c|c|c|}
\hline $\begin{array}{l}\text { Peak } \\
\text { No:" }\end{array}$ & Compound & $\begin{array}{l}\text { Relative } \\
\text { amount }^{b}\end{array}$ & RI. & $\mathbf{R} \mathbf{L}^{\mathbf{C}}$ & $\begin{array}{l}\text { Methyl group } \\
\text { position }\end{array}$ \\
\hline 2 & 5,9-dimethylhexadecane & + & 1691 & 1690 & $5, \omega 8$ \\
\hline 7 & 7,11-dimethylheptadecane & ++ & 1785 & 1792 & $7, \omega 7$ \\
\hline 8 & 6,11-dimethylheptadecane & ++++ & 1794 & 1795 & $6, \omega 7$ \\
\hline 9 & 6,12-dimethylheptadecane & $++t$ & 1796 & 1798 & $6, \omega 6$ \\
\hline 11 & 4,12-dimethylhepladecane & + & 1804 & 1808 & $4, w 6$ \\
\hline 14 & 6,7-dimethylheptadecane & ++ & 1815 & 1815 & \\
\hline \multirow[t]{2}{*}{15} & 5,6-dimethylheptadecane & + & 1821 & 1824 & \\
\hline & 7,11-dimethyloctadecane & tr & 1881 & 1889 & $7, \omega 8$ \\
\hline 20 & 7,12-dimethyloctadecane & ++ & 1887 & 1890 & $7, \omega 7$ \\
\hline 21 & 6,12-dimethyloctadecane & +++ & 1892 & 1893 & 6,07 \\
\hline 22 & 6,13-dimethyloctadecane & +++ & 1896 & 1896 & 6,66 \\
\hline 23 & 5,13-dimethyloctadecane & + & 1899 & 1901 & 5,66 \\
\hline \multirow[t]{5}{*}{25} & 6,7-dimethyloctadecane & $+t+$ & 1915 & 1915 & \\
\hline & 5,6-dimethyloctadecane & tr & 1921 & {$[923$} & \\
\hline & 7,13-dimethylnonadecane & tr & 1986 & 1989 & $7, \omega 7$ \\
\hline & 6,13-dimethylnonadecane & tr & 1991 & 1992 & 6,67 \\
\hline & 6,14-dimethylnonadecane & tr & 1994 & 1996 & $6, w 6$ \\
\hline
\end{tabular}

- Number refers to Figs. 4-7.

- tr: trace amount; + : very minor; ++ : minor; +++ abundant; ++++ : major 'calculated following the additivity principle of KJssin et al. (1986) 
(a)

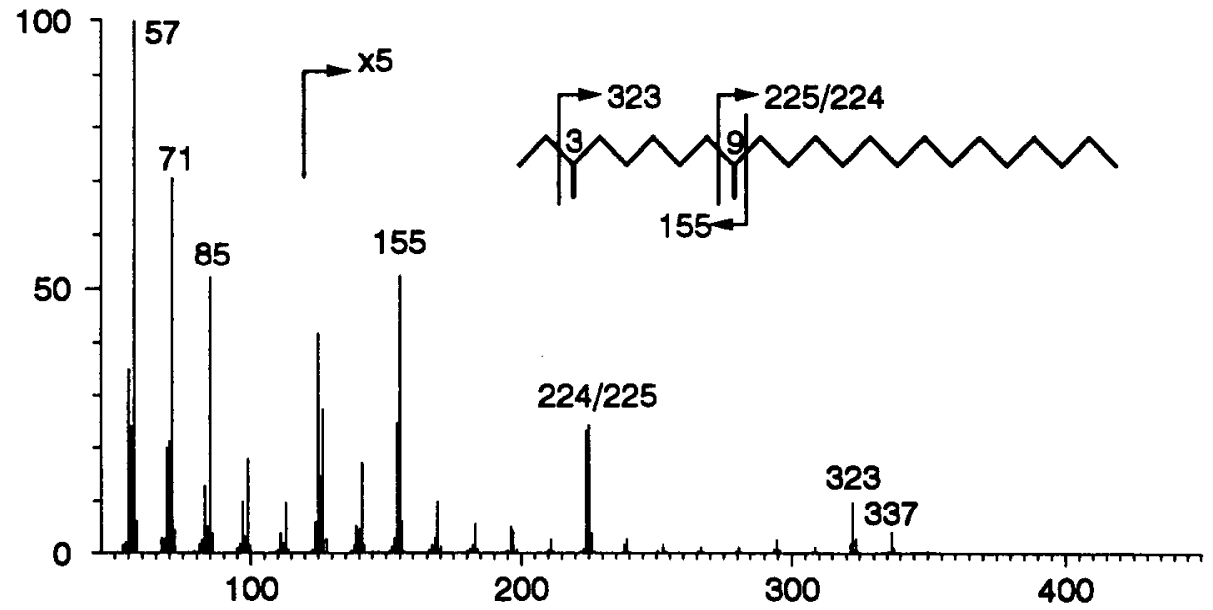

(b)

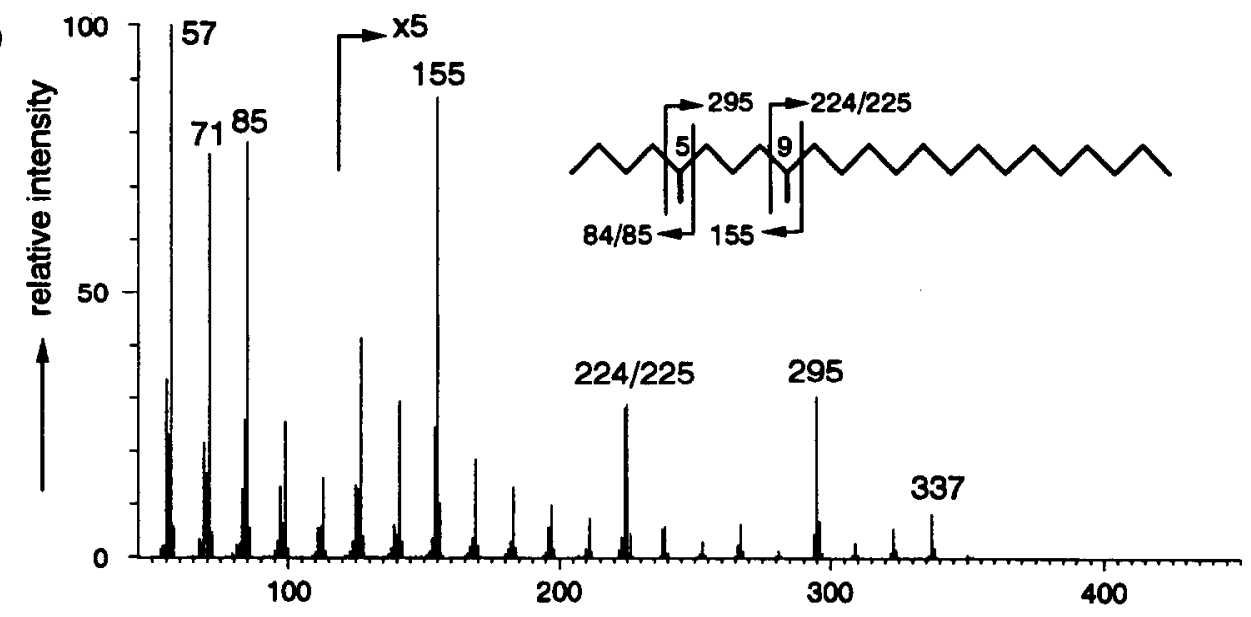

(c)

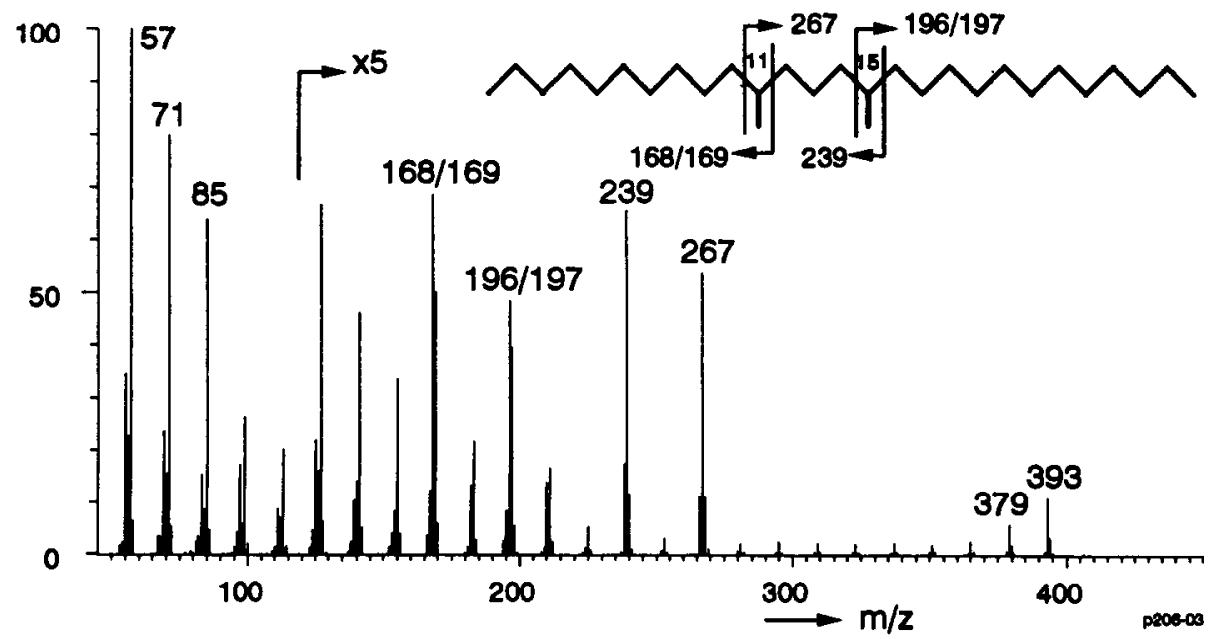

Fig. 3. Mass spectra, subtracted for background, of authentic (a) 3,9-dimethyltricosane (35), (b) 5,9-dimethyltricosane (34), and (c) 11,15-dimethylheptacosane (49).

prised of unresolved mixtures of mid-chain methylalkane isomers but these mixtures are dominated by specific isomers with the methyl group in position 11,13 , or 15 ( see Table 1 ). In addition, minor amounts of 9- and 7-methylalkanes were detected by appropriate mass chromatography. In the longchain MMAs with an even total number of carbon atoms (representing all but three of the MMAs identified) the methyl group is exclusively located at an odd-numbered carbon atom. This very specific distribution of long-chain centrally branched MMA's has to the best of our knowledge never been reported in other geological samples. MMAs with an odd total number of carbon atoms $(36, \underline{44}, \underline{66})$ are only present in relatively low concentrations and possess methyl substituents on both even and odd numbered carbon atoms. 
(a)

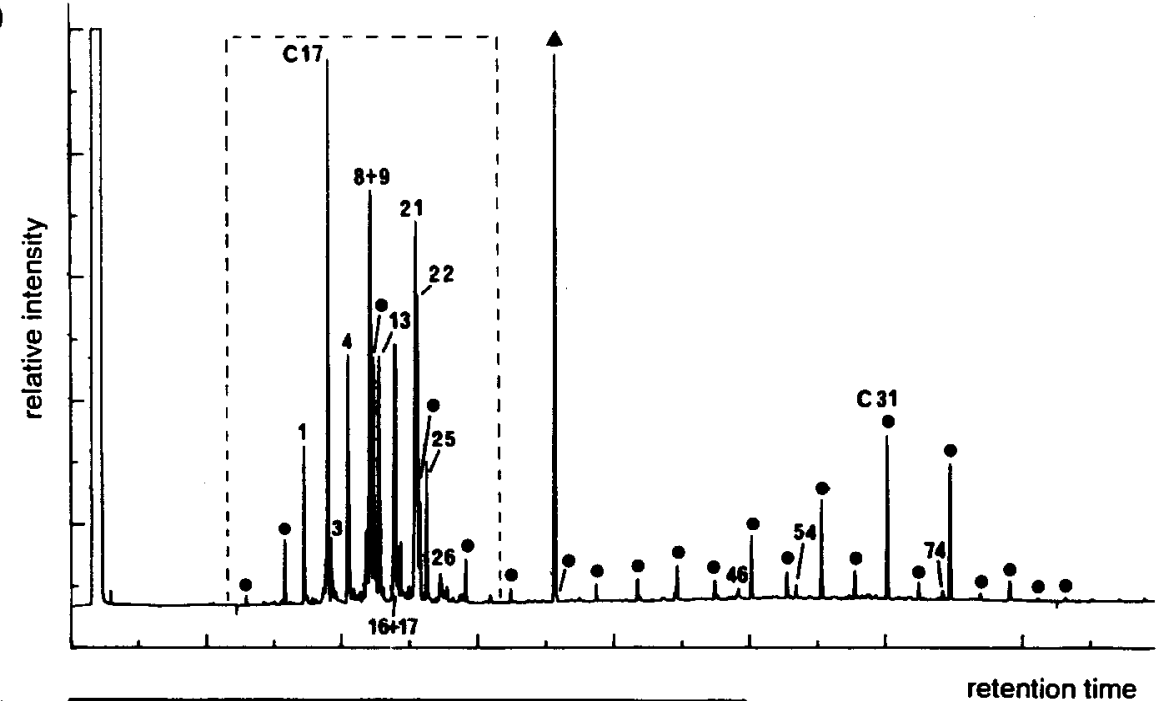

(b)

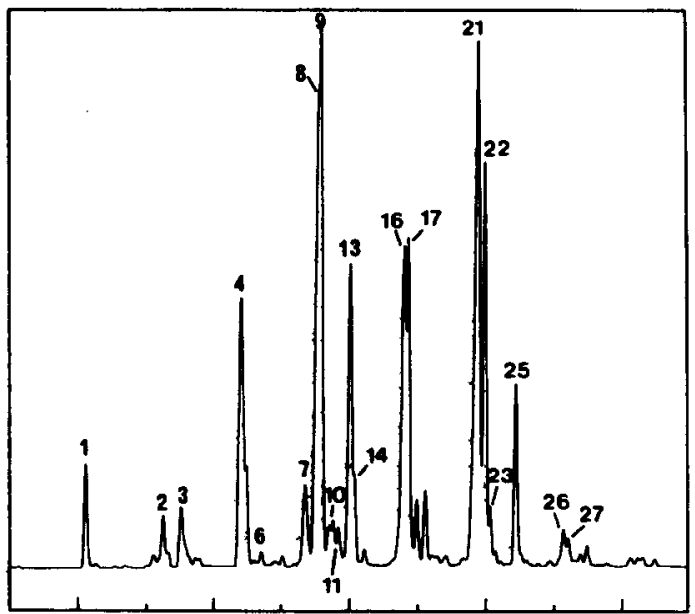

Fig. 4. (Partial) gas chromatograms of (a) the saturated hydrocarbon fraction and (b) the nonadduct of the saturated hydrocarbon fraction of a modern cyanobacterial mat (sample 73180). Numbers refer to compounds listed in Table 1. Filled circles indicate $n$-alkanes. A filled triangle indicates contamination.

\subsubsection{Distribution of long-chain DMAs}

Three homologous series corresponding to unresolved mixtures of DMAs were encountered in the nonadduct of the saturated hydrocarbon fractions of the transgressive cyanobacterial mat (Fig. 7c). All members of these series contain an odd total number of carbon atoms, indicating that the longest chains carrying the methyl substituents also contain an odd number of carbon atoms. The distribution of these DMAs is centered around dimethylheptacosanes and dimethylnonacosanes and range from dimethyltricosanes $\left(C_{25}\right)$ to dimethylnonatriacontanes $\left(\mathrm{C}_{41}\right)$.

The first homologous series (peaks $\underline{35}, 43,53,61,72,78$; Fig. $7 \mathrm{c}$ ) has retention indices 90 Kovats units smaller than the $n$-alkanes with the same molecular weight. Figure $3 a$ shows the mass spectrum of a synthetic authentic standard, 3,9-dimethyltricosane, which coeluted with peak 35 on two different capillary columns. Its mass spectrum is identical to that of peak 35. A related homologous series of DMAs elute slightly after the 3,9-dimethylalkanes and is tentatively identified, on the basis of their mass spectra, as 3,7-dimethylal- kanes. Mass spectra of these compounds are characterized by a fragment at $127 \mathrm{Da}(25 \%)$, indicative of a methyl substituent at $C-7$, and by a fragment $M^{+}-29(5 \%)$ indicative of the location of a methyl substituent at $\mathrm{C}-3$. The elution of this series just after the 3,9-dimethylalkane series is in agreement with the Kovats indices calculated using the additivity principle of Kissin et al. (1986). The mass spectrum of a 3,7dimethylalkane is published as an "unknown compound" by Mycke et al. (1988).

The second homologous series, the 5, $x$-DMAs, $(34,42$, $51,60,71$ ), represents a minor contribution to the hydrocarbon fractions of the buried cyanobacterial mats. The compounds constituting this series have retention indices 115 Kovats units smaller than those of the $\boldsymbol{n}$-alkanes with the same molecular weight. The structural determination was confirmed by coinjection of a synthetic authentic standard, 5,9-dimethyltricosane, which coeluted with peak $\underline{34}$ on two different capillary columns. The mass spectrum of the authentic standard is shown in Fig. 3b. However, comparison of this mass spectrum with the averaged mass spectrum obtained from peak $\underline{34}$ demonstrated that 5,11- and 


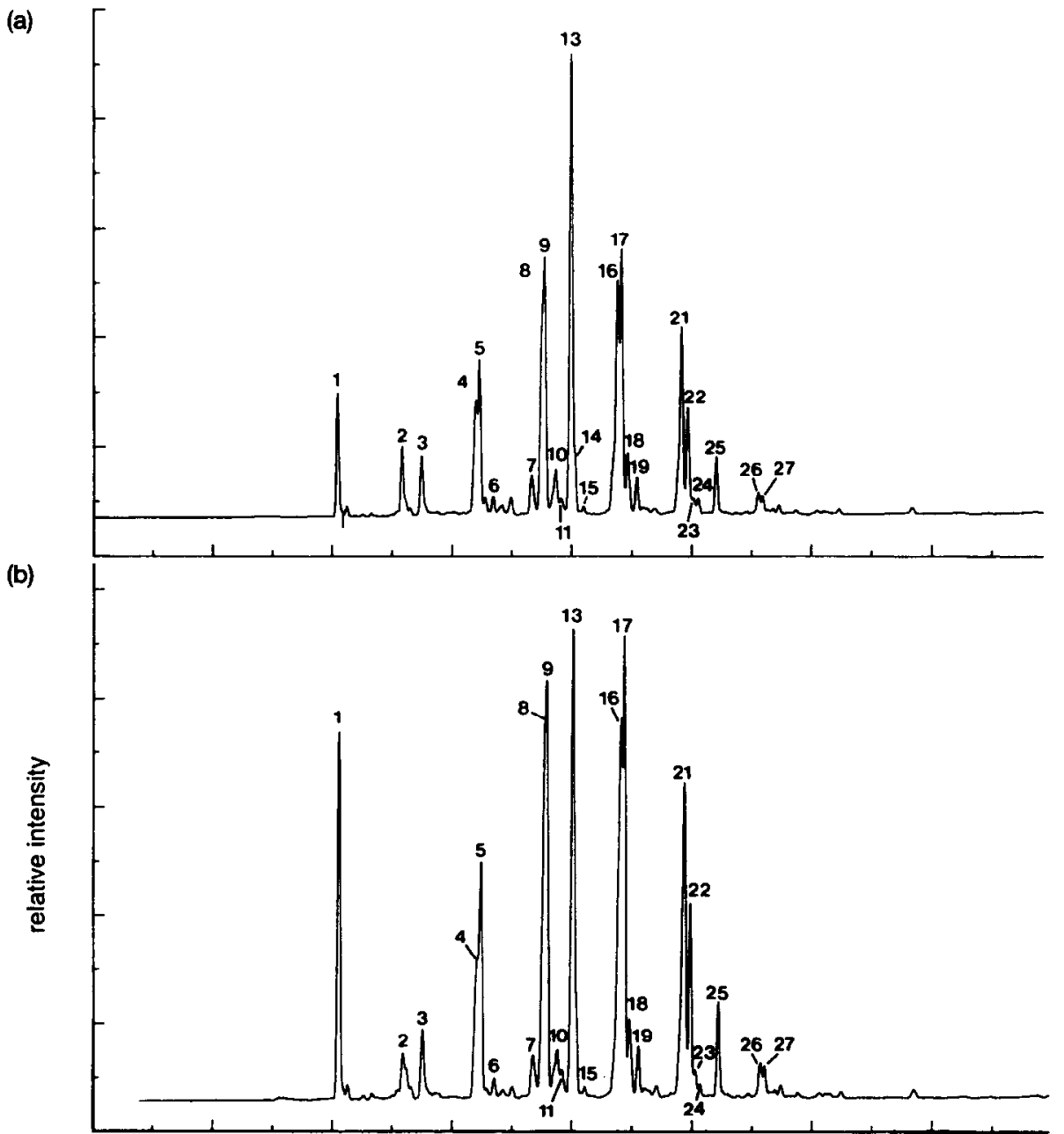

(c)

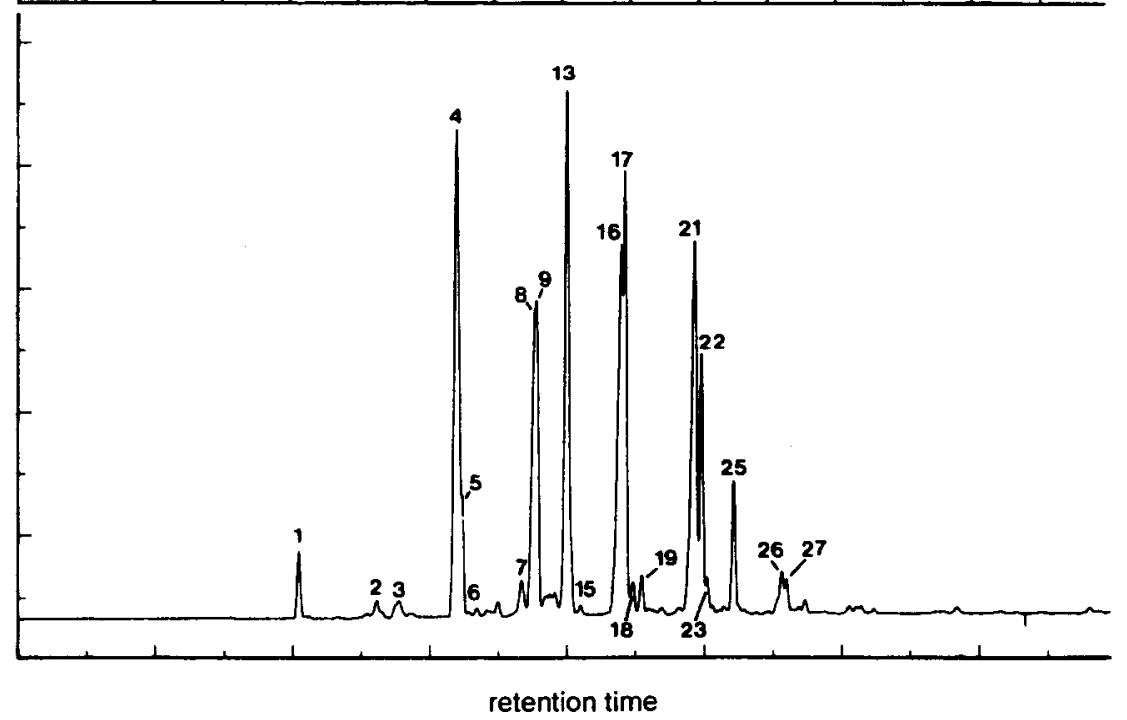

FIG. 5. Partial gas chromatograms of the nonadducts of the saturated hydrocarbon fraction of modern cyanobacterial mats. (a) sample 73280, (b) sample 73282. and (c) sample 73172. Numbers refer to compounds listed in Table 1.

5,13-DMA isomers were also present. Homologs of the latter two series give rise to peak 51 , in which no traces of a 5,9-DMA isomer were detected.
The compounds of the third major homologous series of DMAs, centrally branched DMAs $(40,49,58,69,76,82,84$, 86), have retention indices 117 Kovats units smaller than 


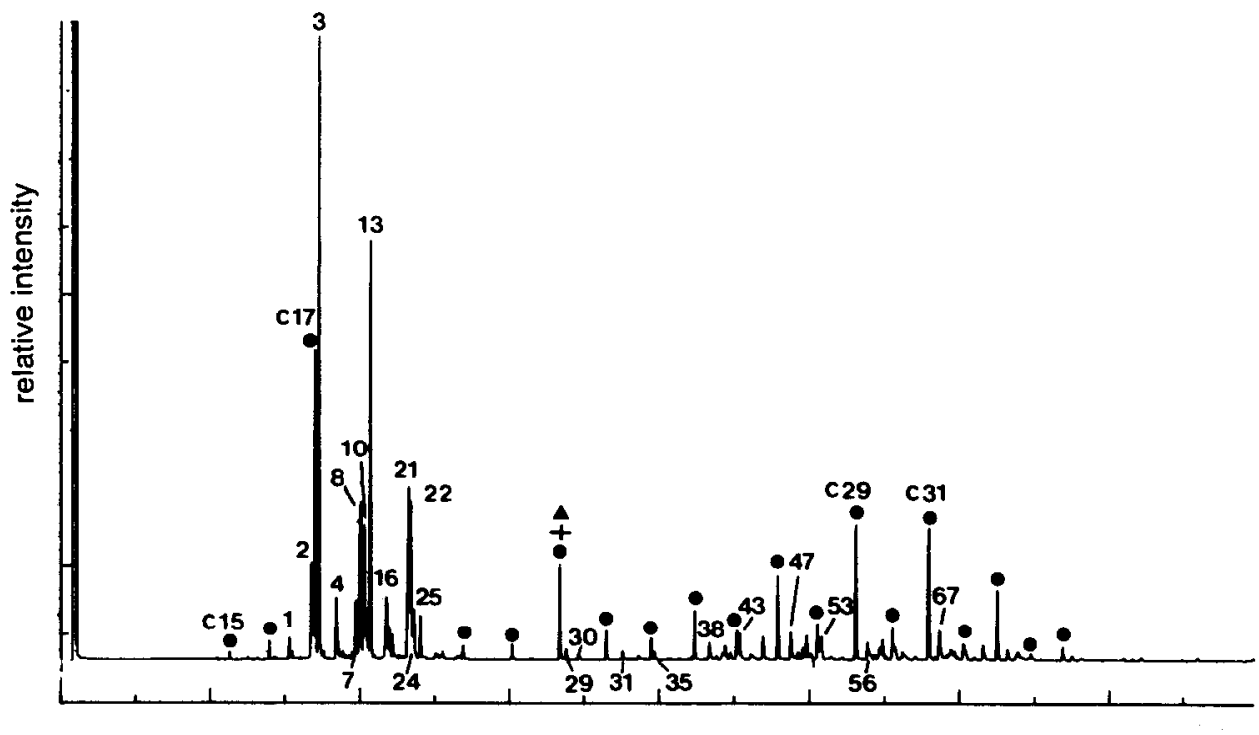

retention time

FIG. 6. Gas chromatogram of the saturated hydrocarbon fractions of a regressive cyanobacterial mat (sample 89705) Numbers refer to compounds listed in Table 1. Filled circles indicate $n$-alkanes. A filled triangle indicates contamination.

those of the $n$-alkanes with the same molecular weight. These compounds are present up to $\mathrm{C}_{45}$. Identification of this homologous series was confirmed by coelution with a synthesized standard of 11,15-dimethylheptacosane on two different capillary columns with peak 49 . Comparison of the mass spectrum of the synthetic authentic standard (Fig. 3c) with that of an averaged mass spectrum of peak 49 indicated that the 11,15-isomer is not the only DMA eluting at this position in the gas chromatogram. A coelution experiment performed with authentic 9,13-dimethylheptacosane revealed that this DMA-isomer elutes slightly later than 11,15-dimethylheptacosane. Comparison of its mass spectrum with the averaged mass spectrum demonstrates that it is only a minor constituent of the $\mathrm{C}_{29}$ mid-chain DMA mixture, which is dominated by 11,15-dimethylheptacosane. In contrast, the $C_{31}$ mid-chain DMA mixture appears to be dominated by the 9,13-DMA isomer $(\underline{58})$.

\subsubsection{Distribution of TMAs}

Trimethylalkanes (TMAs) are minor components of the hydrocarbon fraction of the transgressive cyanobacterial mat $(\underline{37}, 45,55,63,73,79 ;$ Fig. 7c). They have retention indices ca. 170 Kovats units smaller than those of the $n$-alkanes with the same molecular weight. As a consequence they elute within the range of MMAs with one carbon atom less. However, the absence of high-molecular-weight $\left(\mathrm{C}_{32}-\mathrm{C}_{36}\right)$ MMAs with an odd total number of carbon helped to obtain relatively pure mass spectra (Fig. 8).

The mass spectrum of the $\mathrm{C}_{36}$ TMA (Fig. 8a) is identical to the mass spectrum of authentic 3,7,11-trimethyltritriacontane (Martin and McConnel, 1970). The mass spectrum of the peak ascribed to $C_{34}$ TMAs (Fig. 8b) was interpreted in represent a mixture of two isomers, 3,9,15- and 3,11,15-trimethylhentriacontane. The mass spectrum of the $\mathrm{C}_{32}$ TMA peak (Fig. $8 \mathrm{c}$ ) exhibits a clear fragmentation pattern indica- tive of the presence of 3,9,13-trimethylnonacosane. A mass spectrum of the $C_{26}$ TMA peak exhibits diagnostic odd fragments at 127 and $197 \mathrm{Da}$, as well as a $\mathrm{M}^{+}-29$ fragment and was tentatively interpreted as representing 3,7,11-trimethyltricosane. No tentative structure can be proposed for the $C_{28}$ and $C_{30}$ TMAs due to their coelution with some isomers of MMA's with an odd total number of carbon atoms.

All TMAs detected have a longest chain composed of an odd number of carbon atoms and carry the methyl substituents at odd-numbered carbon atoms. They do not form an actual homologous family, but all the compounds of this series detected carry a methyl substituent at C-3.

\section{DISCUSSION}

\subsection{Origin of Short-Chain MMAs and DMAs}

Short-chain centrally branched MMAs in the $C_{15}-C_{20}$ range were identified in monospecific cultures of cyanobacteria. Shiea et al. (1990) reviewed the literature on the occurrence of MMAs in cyanobacteria and reported that MMAs are present in eighteen out of twenty-six of the species studied. Methylheptadecanes (the 4-, 6-, and mainly 7-, and 8methyl isomers) are the most commonly encountered compounds. Because of the frequent occurrence of short-chain MMAs in cultures of cyanobacteria these compounds are considered as cyanobacterial "biomarkers"' when present in sediments. Cyanobacteria are the only micro-organisms known to produce short-chain centrally branched MMAs (Shiea et al., 1990). DMAs have been found once in cyanobacteria by Summons and Jahnke (pers. commun., 1994). They identified 7,10- and 7,11-dimethyl-heptadecanes in cultures of Phormidium luridum.

MMAs and DMAs have been encountered in modern environments in natural samples containing cyanobacteria (for MMA: see review by Shiea et al., 1990). Monomethylalkanes and, more specifically, the 8- and 7-methylheptadecanes have 
(b)

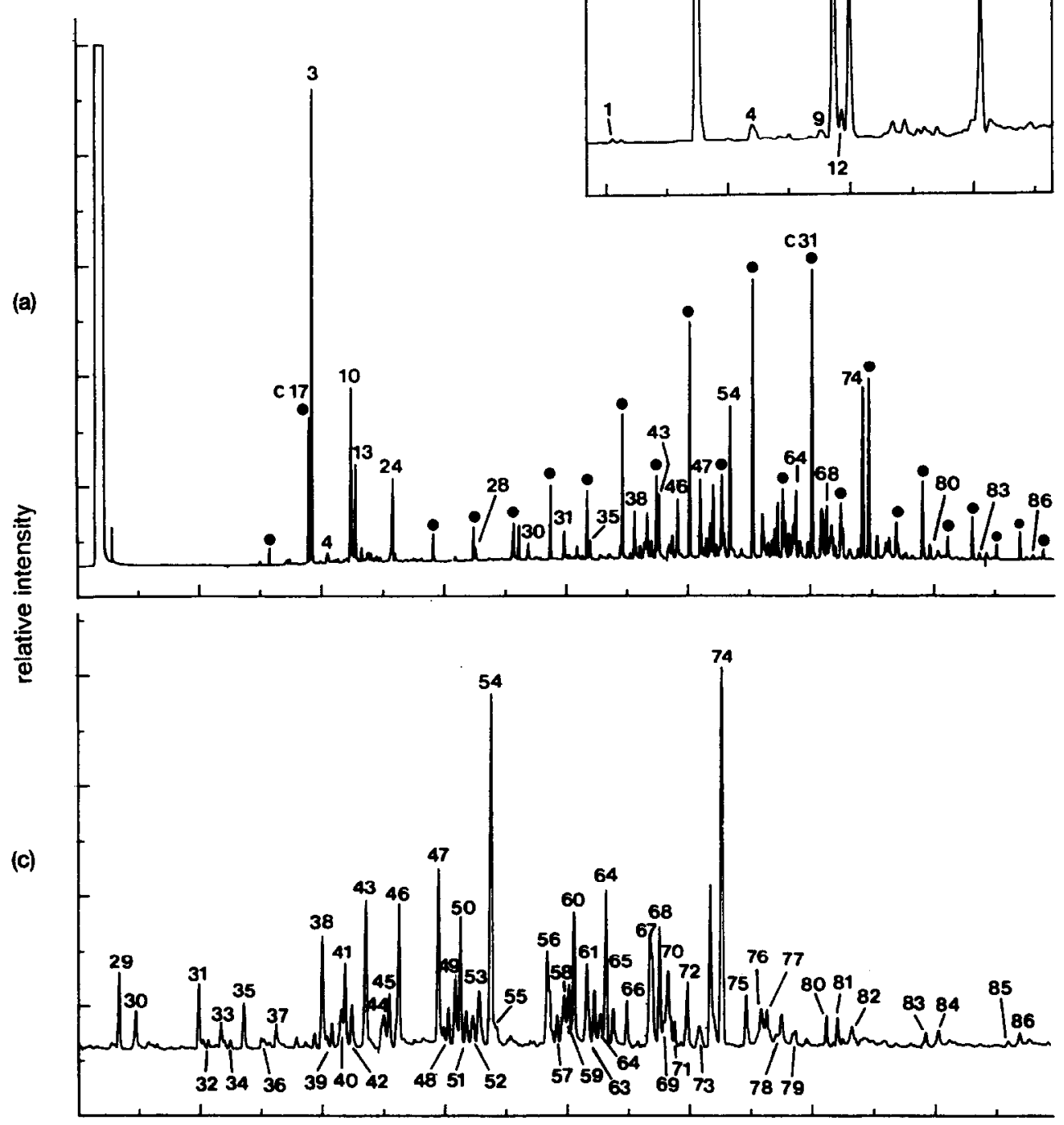

retention time

Fig. 7. (a) Gas chromatogram of the saturated hydrocarbon fraction of a transgressive cyanobacterial mat. (b, c) Partial gas chromatograms of the branched and cyclic fraction of a transgressive cyanobacterial mat, sample 89705. Numbers refer to compounds listed in Table 1. Filled circles indicate $n$-alkanes.

been commonly identified in recent sediments containing cyanobacteria (e.g., Cardoso et al., 1976; Philp, 1980; Boon et al., 1983). A distribution of short-chain MMAs equivalent to that found in Abu Dhabi cyanobacterial mats was observed in the cyanobacterial mats from the Gavish Sabkha (Sinai) by de Leeuw et al. ( 1985). Suites of isomers of MMAs in the
$\mathrm{C}_{17}-\mathrm{C}_{20}$ range were observed in modern cyanobacterial mats from the Pacific atoll of Christmas Island (France) by Boudou et al. (1986a,b) and by Kenig (1991). Cyanobacterial assemblages present in hot springs also produce suites of structural isomers of short-chain MMAs (Robinson and Eglinton, 1990; Shiea et al., 1990, and references therein ). Shiea et al. (1990, 

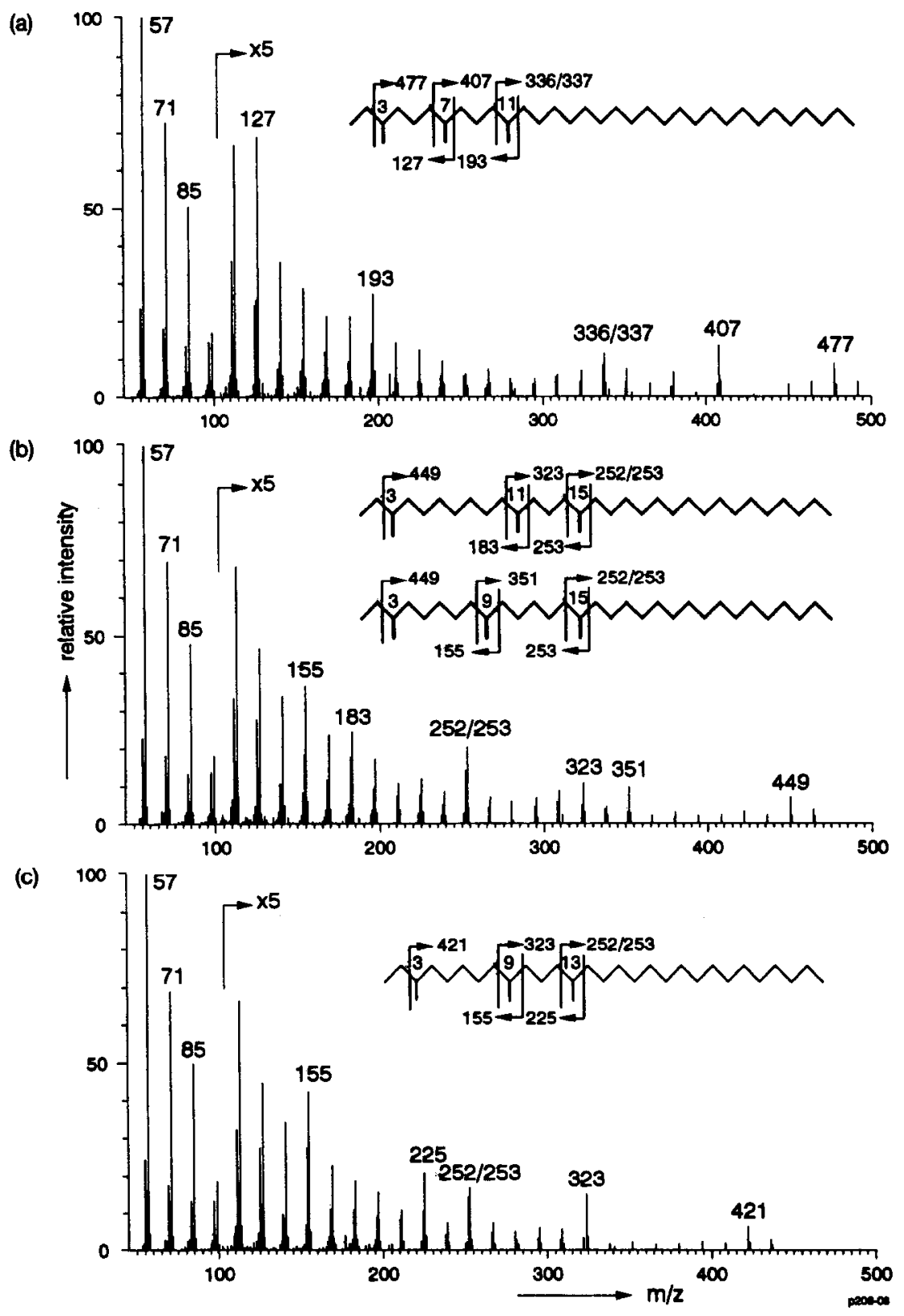

FIG. 8. Mass spectra, subtracted for background, of TMAs tentatively identified as (a) 3,7,11-trimethyltritriacontane (79), (b) a mixture of 3,9,15- and 3,11,15-trimethylhentriacontane (73), and (c) 3,9,13-trimethylnonacosane (63).

1991 ) observed that short-chain MMAs are not present in microbial mats which do not contain cyanobacterial species; this confirms that cyanobacteria are, as far as we know, the only extant organisms, synthesizing MMAs in such biological systems.

In recent studies short-chain DMAs were reported to occur in modern cyanobacterial assemblages. 6,10-Dimethylheptadecane, 7,10-, and 6,10-dimethyloctadecane were tentatively identified by de Leeuw et al. (1985) in the Gavish Sabkha (Sinai) cyanobacterial mats, and a bacterial origin was suggested for these compounds. 6,10-Dimethylheptadecane is the major compound of the hydrocarbon fraction of a modern cyanobacterial mat from the French Polynesian atoll of Hao (Kenig, 1991). The mass spectra shown by de Leeuw et al.
(1985) and Kenig (1991) for 6,10-dimethylheptadecane are identical to that reinterpreted here as that of a 6,12-dimethylheptadecane (Fig. 1a). Recently, Shiea et al. (1990) tentatively identified 5,6-, 4,5-, 3,12-, 5,12-, and 4,13-dimethylheptadecane in hot spring microbial mats. By the use of GCMS-MS, Robinson and Eglinton (1990) also tentatively identified 4,13-, 5,13-, 5,12-, and 6,12-dimethyl-heptadecane as well as 7,12-dimethyloctadecane in other hot spring microbial mats. The presence of 5,13-dimethylheptadecane was confirmed by synthesis of an authentic standard (Carter et al., 1989). Shiea et al. (1990) and Robinson and Eglinton (1990) observed that these DMAs have the same carbon chain length distribution as the MMAs and, consequently, suggested a similar biological origin. The results presented in this report are 
in agreement with this observation. Short-chain MMAs and DMAs of Abu Dhabi modem and Holocene cyanobacterial mats, thus, both derive from cyanobacterial sources. Their stable carbon isotopic compositions are in agreement with an origin from cyanobacteria (F. Kenig and J. M. Hayes, unpubl. data).

In Abu Dhabi cyanobacterial mats, the relative concentration of the short-chain MMAs and DMAs decreases progressively with increasing age (Figs. 4, 6, 7). Only traces of these compounds were detected in the transgressive cyanobacterial mat. Their disappearance, accompanied by a dramatic relative decrease of low-molecular-weight $n$-alkanes could result from biodegradation processes during early burial. A similar trend was previously observed by Boon et al. (1983) in cyanobacterial mats of Solar lake. Robson and Rowland (1988) demonstrated that bacteria preferentially degrade linear compounds or methyl-branched compounds rather than isoprenoids, highly branched isoprenoids and cyclic compounds.

\subsection{Origin of Long-Chain MMAs, DMAs, and TMAs}

No long-chain DMAs and TMAs have been identified in cyanobacterial cultures and, until this report, in recent natural cyanobacterial assemblages. As far as we know the long-chain MMAs, DMAs, and TMAs are here reported for the first time in recent sedimentary organic matter. Only one cyanobacterium, Spirulina platensis, is reported to produce traces of 2-, 7-, and 8-MMAs in the $\mathrm{C}_{17}-\mathrm{C}_{28}$ range (Paoletti et al., 1976). An homologous family of 3,9-DMAs and centrally branched MMAs with carbon number ranging between $C_{16}$ and $C_{35}$, was tentatively identified in leaf waxes (Bricskorn and Beck, 1970). But none of these homologous series of compounds fit the specific distributions of MMAs and DMAs present in the Abu Dhabi mats.

MMAs, DMAs, and TMAs are frequently encountered in the surface lipids and waxes of insects ( see reviews by Jackson and Blomquist, 1976; Nelson, 1978; Blomquist et al., 1987; Nelson and Blomquist, 1995, and references therein). They play a fundamental role in insect survival since they participate in desiccation control, in protection against microorganisms, in resistance to abrasive damages and in chemical communication ( sex attractant, nest-mate, and caste identification). Branched hydrocarbons identified in insect waxes display a number of particularities. The vast majority of these molecules have methyl-substituents at odd numbered carbon atoms and possess a longest aliphatic chain with an odd number of carbon atoms. Centrally branched MMAs in insects have carbon lengths variable as a function of the species analyzed but generally vary between twenty to fifty carbon atoms. DMAs in insect waxes also have a broad carbon range $\left(\mathrm{C}_{25}-\mathrm{C}_{55}\right)$. A majority of insects have DMAs with methyl substituents separated by three methylene units and located at odd numbered carbon atoms $(3,7-; 5,9-; 11,15-; 13,17-$; 15,19-DMA; Blomquist et al., 1987). However, 5, 7, and 9 methylene units between methyl branches (as in 3,9-; 3,11-; 5,11-; 5,13-; 5,15-; 5,17-; 9,15-; 9,17-DMA) have also been observed frequently (e.g., Jurenka et al., 1989; Page et al., 1990a,b; Kaib et al., 1993). Odd DMAs, with the longest chains containing an odd number of carbon atoms, are dominant over compounds with an even number of carbon atoms.
DMAs with an even number of carbon atoms carry the methyl substituents at even numbered carbon atoms (e.g., Nelson and Sukkestad, 1975; Pomonis, 1989). These were only identified in a limited number of insect species. Homologous families of centrally branched DMAs (9,13-; 11,15-; 13,17-DMA) are the most common but other DMAs (3,7-; 5,9-DMA) can be abundant in certain species. TMAs have been reported in lipid assemblages of surface lipids of several groups of insects (e.g., Martin and McConnel, 1970; Jackson and Blomquist, 1976; Nelson, 1978; Page et al., 1990b). Two families can be separated on the basis of the location of the methyl substituents. The first family carries the methyl substituents near the end of the chain (3,7,11-TMAs and 4,8,12-TMA) and a second family carries the methyl substituents at centrally located carbon atoms. Both these families are characterized by location of the methyl substituents mainly at odd numbered carbon atoms and are dominated by molecules with an even total number of carbon atoms. Methyl substituents are mainly separated by three methylene groups [3,3] but TMAs with [3,5] and $[3,7]$ spacings between methyl substituents were identified as well (e.g., Page et al., 1990b).

The distributions of long-chain MMAs, DMAs, and TMAs of Abu Dhabi cyanobacterial mats perfectly match the distributions of these compounds in insect waxes, both in terms of carbon range and in terms of isomer distribution. Moreover, Kenig et al. (1994) observed that long-chain MMAs and DMAs of the transgressive cyanobacterial mat were very significantly ${ }^{13} \mathrm{C}$ enriched relative to total organic carbon, thus, excluding cyanobacteria as potential sources for these compounds. If they were, depletion in ${ }^{13} \mathrm{C}$ relative to total mat carbon would be expected (Hayes, 1993). This ${ }^{13} \mathrm{C}$ enrichment of MMAs and DMAs was explained by an origin from insects grazing on the cyanobacterial mats (Kenig et al., 1994). Insects are commonly enriched relative to their carbon source by 2\%o (De Niro and Epstein, 1978) and their cuticular hydrocarbons have been reported to be enriched by $1 \%$ (Des Marais et al., 1980).

Insect burrows were observed in intertidal and supratidal modern sediments of the Abu Dhabi sabkha. The transgressive cyanobacterial mat studied here was also intensively burrowed. Although the excavators are not precisely known, insects are the more likely candidates. Insects and insect larvae are known as primary consumers of cyanobacterial mats of Solar lake and the Gavish sabkha (Sinai; Gerdes et al., 1985) and of microbial mats of Andros Island (Bahamas; Garrett, 1970). They are abundant in intertropical coastal hypersaline environments such as Laguna Guerero (Mexico; Javor and Castenholz, 1984). In the sediments of the Gavish sabkha, a number of insect were observed (Gerdes et al., 1985), even though none of the molecular components typical of insects were identified in the microbial mats (de Leeuw et al., 1985). These insects are dominated by members of genus Bledius, which dig characteristic tunnels. Their distribution appears to be limited by the groundwater table level (Gerdes et al., 1985). It is likely that the insect distribution in the sediments of Abu Dhabi sabkha is also limited by such constraints. Therefore, it is more likely to find insect remains in microbial mats located high in the intertidal zone. However, without the precise identification of the species or group of species responsible for the abundance of the long-chain branched hy- 
drocarbons in the cyanobacterial mats, it is not possible to predict the distribution of their remains in the sediments.

Insects have never been cited as contributors to sedimentary organic matter. Their soft bodies and unmineralized exoskeletons result in a poor fossil record (Robinson and Kaesler, 1987). However, their cuticular waxes contain compounds particularly refractory to biologically mediated oxidation and, in consequence, are resistant to mineralization. In terms of total organic carbon (TOC) the contribution of insects may be negligible but considering the preservation potential of their waxes, even in dispersed form, the contribution of their lipids to the hydrocarbon fraction of sediments is plausible.

\subsection{Occurrence and Significance of MMAs, DMAs, and TMAs in Sediments and Oil}

Centrally branched MMAs have been described in several pre-Ordovician oils (e.g., Hoering, 1976, 1981; Klomp, 1986; Fowler and Douglas, 1987), oil seeps (Hieshima and Pratt, 1991), and sediments (Summons et al., 1988a,b). In these oils and sediments, the methyl groups in these MMAs are located at both even and odd numbered carbon atoms. Neither an odd or an even carbon number predominance is observed. Thus, they cannot be related to the MMAs identified in Abu Dhabi cyanobacterial mats.

Long-chain 3,7-dimethylalkanes, with an odd total number of carbon atoms, ranging from $C_{21}$ to $C_{33}$ were tentatively identified in Permian shales ("Brandschiefer series") of West Germany (Dill et al., 1988). The non-identified compounds reported by Mycke et al. (1988), among hydrogenation products of non soluble organic matter of the Precambrian Shungit Coal (Russia) and of the "massive sulfide", from the Mount Isa Formation (Australia), have exactly the same mass spectra and the same retention times as the 3,7dimethylalkanes tentatively identified in the Abu Dhabi cyanobacterial mats. These compounds range from $C_{17}$ to $C_{31}$ and, the odd carbon-numbered compounds are dominant over even ones. Mycke et al. (1988) suggest that the presence of these compounds may be related to the original organic matter of these sediments, i.e., archaebacteria or primitive algae. The 3,7-DMAs in the Abu Dhabi mats are present in trace amounts only and exclusively contain an odd number of carbon atoms. Hence, an origin from insect waxes of the 3,7-DMAs in these ancient samples is very unlikely. In the Precambrian sample this has not to be expected anyway, because arthropods only appeared during the very late Precambrian and insects after the Devonian (Robinson and Kaesler, 1987).

No TMAs in the carbon range of those identified in insects and in the cyanobacterial mats of Abu Dhabi have been identified in ancient sediments and oils.

We, therefore, conclude that our present findings, unfortunately, do not throw light on the origins of methylalkanes in ancient sediments. However, it cannot be excluded that refractory components from waxes of insects have been preserved in the geological record and contribute to the hydrocarbon fraction of some ancient sediments.

\section{CONCLUSIONS}

In Abu Dhabi cyanobacterial mats, short-chain $\left(\mathrm{C}_{16}-\mathrm{C}_{21}\right)$ MMAs and DMAs and long-chain $\left(\mathrm{C}_{24}-\mathrm{C}_{45}\right)$ MMAs, DMAs, and TMAs form two groups of distinct origins. The shortchain MMAs and DMAs are most likely derived from cyanobacteria. The long-chain MMAs, DMAs, and TMAs exhibit particular distributions, dominated by components with the longest chain containing an odd number of carbon atoms and positions of methyl substituents at odd numbered carbon atoms. These compounds are most likely derived from insect waxes, the contribution of which to sedimentary organic matter is noted here for the first time.

Acknowledgments-We gratefully acknowledge the Abu Dhabi authorities for their cooperation. We thank TOTAL ABK for local support and TOTAL and ADNOC for permission to publish this paper. We also thank Dr. R. Boichard and Dr. J. L. Oudin of TOTAL, Prof. B. H. Purser, Dr. J. C. Plaziat, and Dr. F. Baltzer of Orsay Paris XI University for their help in the field and considerable sedimentological advice in the Abu Dhabi Sabkha project. We acknowledge the help of Mrs. M. Bernon, Mrs. M. Da Silva, and Mrs. M. Fabre for their valuable assistance to $F$. $K$. during his stay at IFP. Dr. J. G. Pomonis is gratefully acknowledged for supplying the authentic 9,13dimethylheptacosane. This work was partly supported by a PIONIER grant to JSSD from the Netherlands Organization for Scientific Research (NWO). This is NIOZ Division of Marine Biochemistry contribution no. 206.

Editorial handling: R. E. Summons

\section{REFERENCES}

Adringa H., Hanekamp J., and Brandsma L. (1990) Copper halidecatalysed mono substitution in $\alpha, \omega$-dibromoalkanes by Grignard reagents. Synth. Commun. 20, 2349-2351.

Augustynowicz M., Malinski E., Warnke Z., Szafranek J., and Nawrot J. (1987) Cuticular hydrocarbons of the German cockroach, Blattella germanica L. Comp. Biochem. Physiol. 86B, 519-523.

Barrick R. C., Hedges J. 1., and Peterson M. L. ( 1980 ) Hydrocarbon geochemistry of the Puget Sound region-l. Acyclic sedimentary hydrocarbons. Geochim. Cosmochim. Acta 44, 1349-1362.

Blomquist G. J., Nelson D. R., and De Renobales M. (1987) Chemistry, biochemistry, and physiology of insect cuticular lipids. Arch. Insect Biochem. Physiol. 6, 227-265.

Boon J. J., Hines H., Burlingame A. L., Klok J., Rijpstra W. I. C., de Leeuw J. W., Edmunds K. E., and Eglinton G. ( 1983) Organic geochemistry of Solar Lake laminated cyanobacterial mats. In Advances in Organic Geochemistry 1981 (ed. M. Bjorøy et al.), pp. 207-227. Wiley.

Boudou J. P., Trichet J., Robinson N., and Brassell S. C. (1986a) Profile of aliphatic hydrocarbons in a recent Polynesian Microbial Mat. Intl. I. Env. Anal. Chem. 26, 137-155.

Boudou J. P., Trichet J., Robinson N., and Brassell S. C. (1986b) Lipid composition of a recent Polynesian microbial mat sequence. In Advances in Organic Geochemistry 1985 (ed. D. Leythaeuser and J. Rulkötter); Org. Geochem. 10, 705-709.

Brieskorn C. H. and Beck K. R. (1970) Die Kohlenwasserstoffe des Blattwachses von Rosmarinus officinalis. Phytochemistry 9, 16331640.

Brophy J. J., Cavill G. W. K., Davies N. W., Gilbert T. D., Philp R. P., and Plant W. D. (1983) Hydrocarbon constituents of three species of Dolichoderine ants. Insect Biochem. 13, 381-389.

Burne R. V. and Moore L. S. ( 1987) Microbialites: Organosedimentary deposits of benthic microbial communities. Palaios 2, 241254.

Cardoso J. N., Brooks P. W., Eglinton G., Goodfellow R., Maxwell J. L., and Philp R. P. (1976) Lipids of recently deposited algal mats at Laguna Mormona, Baja California. In Environmental Biogeochemistry: Carbon, Nitrogen, Phosphorous, Sulphur and Selenium Cycles (ed. J. O. Nriagu), pp. 149-174. Ann Arbor Science.

Cardoso J. N., Watts C. D., Maxwell J. R., Goodfellow R., Eglinton G., and Golubic S. (1978) A biogeochemical study of the Abu 
Dhabi algal mats: a simplified ecosystem. Chem. Geol. 23, 273291.

Carter J. F., Recka J., and Robinson N. ( 1989) The use of GC-MSMS for the characterisation of naturally occurring methylalkanes. Biomed. Env. Mass Spectrom. 18, 939-941.

Corey E. J. and Suggs J. W. (1975) Chromium oxidations in organic chemistry. Tetrahedron Lett. 31, 2647-2650.

De Leeuw J. W., Sinninghe Damsté J. S., Klok J., Schenck P. A., and Boon J. J. (1985) Biogeochemistry of Gavish sabkha sediments I. Studies on neutral reducing sugars and lipid mojeties by gas chromatography-mass spectrometry. In Hypersaline Ecosystems (ed. G. M. Friedman and W. E. Krumbein); Ecological Studies 53, 350-367. Springer-Verlag.

De Niro M. J. and Epstein S. (1978) Influence of diet on the distribution of carbon isotopes in animals. Geochim. Cosmochim. Acta 42, 495-506.

Des Marais D. J., Mitchell J. M., Meinchein W. G., and Hayes J. M. (1980) The carbon isotope biogeochemistry of the individual hydrocarbons in bat guano and the ecology of the insectivorous bats in the region of Carlsbad, New Mexico. Geochim. Cosmochim. Acta 44, 2075-2086.

Dill H., Teschner M., and Wehner H. (1988) Petrography, inorganic geochemistry of lower Permian carbonaceous fan sequences ("Brandschiefer series")-Federal Republic of Germany: constraints to their paleogeography and assessment of their source rock potential. Chem. Geol. 67, 307-325.

Dunlop R. W. and Jefferies P. R. (1985) Hydrocarbons of the hypersaline basins of Shark Bay, Western Australia. Org. Geochem. 8, 313-320.

Evans G., Schmidt V., Bush P., and Nelson H. (1969) Stratigraphy and geologic history of the sabkha, Abu Dhabj, Persian Gulf. Sedimentology 12, 145-159.

Fehler S. W. G. and Light R. L. ( 1970) Biosynthesis of hydrocarbons in Anabaena Variabilis. Incorporation of (methyl C14) and (Methyl H2) methionine into 7- and 8-methylheptadecane. Biochem. 9, 418-422.

Fowler M. G. and Douglas A. G. (1987) Saturated hydrocarbon biomarkers in oils of late Precambrian age from Eastern Siberia. Org. Geochem. 11, 201-213.

Garrett P. (1970) Phanerozoic stromatolites: noncompetitive ccologic restrictions by grazing and burrowing animals. Science 169, 171- 173 .

Gelpi E., Schnejder H., Mann J., and OTo J. ( 1970) Hydrocarbons of geochemical significance in microscopic algae. Phytochem. 9, 603-612.

Genin E., Jullien R., and Knowles E. ( 1988) Spectrometrie de masse des dimethylalkanes: influence de la temperature de la chambre d'ionisation et mise en evidence d'une fragmentation secondaire caracteristisque. Analusis 16, 186-193.

Gerdes G., Spira J., and Dimentman C. (1985) The fauna of the Gavish Sabkha and the Solar Lake- a comparative study. In $H y$ persaline Ecosystems (ed. G. M. Friedman and W. E. Krumbein); Ecological Studies 53, 322-345. Springer-Verlag.

Gibbons M. J. (1978) The Geochemistry of Sabkha and Related Deposits. Ph.D. thesis, Univ. Newcastle upon Tyne.

Guo L. and Blomquist G. J. (1991) Identification, accumulation, and biosynthesis of the cuticular hydrocarbons of the southern armyworm, Spodoptera eridania (Cramer) (Lepidoptera: Noctuidae). Arch. Insect Bioch. Physiol. 16, 19-30.

Han J. and Calvin M. (1970) Branched alkanes from Blue-Green algae. Chem. Commun., 1490-1491.

Han J., McCarthy E. D., Calvin M., and Benn M. H. ( 1968) Hydrocarbon constituents of the Blue-green algae. Nostoc muscorum, Anacystic nidulans, Phormidium luridum and Chlorogloea fritschii. J. Chem. Soc. C, 2785-2791.

Hayes J. M. ( 1993) Factors controlling ${ }^{13} \mathrm{C}$ contents of sedimentary organic compounds: Principles and evidence. Mar. Geol. 113, $111-125$.

Hebanowska E., Malinski E., Pihlaja K., Nawrot J., Ruszkowska M., Pihlaja K., and J. Szafranek (1989) The composition of the cuticular hydrocarbons of the cereal aphids Sitobion avenae $F$. (Homoptera, Aphidae). Comp. Biochem. Physiol. 94B, 723-727.
Hieshima G. B. and Pratt L. M. (1991) Sulfur/carbon ratios anc extractable organic matter of the Middle Proterozoic Nonesucr Formation, North American Mid-continent Rift. Precamb. Res. 54 65-79.

Hoering T. C. (1976) Molecular fossils from the Precambrian Nonesuch shale. Carnegie Inst. Wash. Yearb. 75, 806-813.

Hoering T. C. (1981) Monomethyl, acyclic hydrocarbons in petroleum and rock extracts. Carnegie Inst. Wash. Yearb. 80, 389-394.

Holzer G., Oro J., and Tornabene T. G. (1979) Gas chromatographic. mass spectrometric analysis of neutral lipids from methanogenic and thermoacidophylic bacteria. J. Chromatogr. 186, 795-809.

Jackson L. L. and Blomquist G. J. (1976) Insect waxes. In Chemistry and Biochemistry of Natural Waxes (ed. P. E. Kolattukudy), pp. 201-233. Elsevier.

Jackson M. J., Powell T. G., Summons R. E., and Sweet I. P. ( 1986) Hydrocarbon show and petroleum source rocks in sediments as old as $1.7 \times 10^{9}$ years. Nature $322,727-729$.

Javor B. J. and Castenholz R. W. (1984) Invertabrate grazers of microbial mats, Laguna Guerero Negro, Mexico. In Microbia Mats: Stromatolites (ed. Y. Cohen et al.); MBL Lectures in Biol. ogy 3, 85-94. Alan R. Riss.

Jurenka R. A., Schal C., Burns E., Chase J., and Blomquist G. J (1989) Structural correlation between cuticular hydrocarbons and female contact sex pheromone of German cockroach Blatella ger. manica. J. Chem. Ecol. 15, 939-949.

Kaib M., Heinze J., and Ortius D. (1993) Cuticular hydrocarbon profiles in the slave-making ant Harpagonexus sublaevis and its hosts. Naturwissenchafien 80, 281-285.

Kendall C. G. ST. C. and Skipwith BTP. A. D'E. (1968) Recen algal mat of a Persian Gulf lagoon. J. Sediment. Petrol. 38, 10401058.

Kenig F. (1991) Sédimentation, distribution et diagenèse de la matière organique dans un environnement carbonaté hypersalin: le système lagune sabkha d'Abu Dhabi (E.A.U.). Thése de Doctoral de l'Université d'Orléans, France; Institut Français du Pétrole. Rueil Malmaison, France.

Kenig F., Huc A. Y., Purser B. H., and Oudin J. L. (1990) Sedimentation, distribution and diagenesis of organic matter in a recen! carbonate environment, Abu Dhabi, U.A.E. In Advances in Organic Geochemistry 1989 (ed. F. Behar and B. Durand); Org. Geochem. 16, 735-747.

Kenig F., Sinninghe Damsté J. S., de Leeuw J. W., and Hayes J. M. (1994) Molecular palaeontological evidence for wood-web relationships. Naturwissenschafien 81, 128-130.

Kinsmann D. J. J. and Park R. K. (1976) Algal belt and coastal sabkha evolution, Trucial Coast, Persian Gulf. In Stromatolites (ed. M. H. Walter); Developments in Sedimentology 20, pp. 421 433. Elsevier.

Kissin Y. V. (1987) Catagenesis and composition of petroleum: Or. igin of n-alkanes and isoalkanes in petroleum crudes. Geochim. Cosmochim. Acta 51, 2445-24567.

Kissin Y. V., Feulmer G. P., and Payne W. B. (1986) Gas chromatographic analysis of polymethyl substituted alkanes. J. Chrom. Science 24, $164-169$.

Klomp U. C. (1986) The chemical structure of a pronounced series of iso-alkanes in South Oman crudes. In Advances in Organic Geo. chemistry 1985 (ed. D. Leythaeuser and J. Rulkötter); Org. Geo. chem. 10, 807-814.

Kolattukudy P. E. (1976) Chemistry and Biochemistry of Natura Waxes. Elsevier.

Lockey K. H. (1984) Hydrocarbons of adult Zophosis (Gyrosis) species and Sophosis (Onychosis) gracipiles (Deyrolle) (Coleoptera Tenebrionidae ). Insect Biochem. 14, 645-656.

Lockey K. H. and Dularay B. (1986) Cuticular methylalkanes of adult cockroaches Blatta orientalis and Periplaneta americana. Comp. Biochem. Physiol. 85B, 567-572.

Lockey K. H. and Oraha V. S. (1990) Cuticular lipids of adult Lo. custa migratoria migratoriodes ( $R$ and $F$ ), Schistocerca gregaric (Forskal) (Acrididae) and other othoptheran species- Il. Hydrocarbons. Comp. Biochem. Physiol. 95B, 721-744.

Martin M. M. and McConnel J. G. (1970) The alkanes of the Ant Atta columbica. Tetrahedron 26, 307-319. 
McCarthy E. D., Han J., and Calvin M. ( 1968) Hydrogen atom transfer in mass spectrometric fragmentation patterns of saturated aliphatic hydrocarbons. Anal. Chem. 40, 1475-1480.

Mycke B., Michaelis W., and Degens E. T. (1988) Biomarkers in sedimentary sulfide of Precambrian age. In Advances in Organic Geochemistry 1987 (ed. L. Mattavelli and L. Novelli); Org. Geochem. 13, 619-625.

Nelson D. R. ( 1978) Long-chain methyl branched hydrocarbons: Occurence, biosynthesis and function. Adv. Insect. Physiol. 13, 1-33.

Nelson D. R. and Blomquist G. J. (1995) Insect waxes. In Waxes: Chemistry, Molecular Biology and Functions (ed. R. J. Hamilton) pp. 1-129. The Oily Press, Dundee.

Nelson D. R. and Sukkestad D. R. (1975) Normal and branched alkanes from cast skins of the grasshopper Schistocerca vaga (Scudder). J. Lipid Res. 16, 13-18.

Page M., Nelson L. J., Haverty M. I., and Blomquist G. J. ( 1990a) Cuticular hydrocarbons as chemotaxonomic charaters for Bark Beetles: Dentroctonus ponderosae, $D$. jeffreyi, $D$. brevicomis, and D. frontalis (Coleoptera: Scolytidae). Ann. Entomol. Soc. Amer. 83, 892-901.

Page M., Nelson L. J., Haverty M. I., and Blomquist G. J. (1990b) Cuticular hydrocarbons of eight species of north american cone beetles Conophthorus Hopkins. J. Chem. Ecol. 16, 1173-1198.

Paoletti C., Pushparaj B., Florenzano G., Capella P., and Lercker G. (1976) Unsaponifiable matter of green and blue green algal lipids as a factor of biochemical differentiation of their biomasses: 1 Total unsaponifiable hydrocarbon fraction. Lipids 11, 258-265.

Park R. K. (1977) The preservation potential of some recent stromatolites. Sedimentol. 24, 485-506.

Philp R. P. (1980) Comparative organic geochemical studies of recent algal mats and sediments of algal origin. In Biogeochemistry of Ancient and Modern Environments (ed. P. A. Trudinger and M. R. Walter), pp. 173-185. Springer-Verlag.

Pomonis G. J. (1989) Cuticular hydrocarbons of the screwworm Cochliomyia hominivorax (Diptera: calliphorodae): Isolation, identification and quantification as a function of age sex and irradiation. J. Chem. Ecol. 9, 2301-2316.

Pomonis J. G., Fatland C. F., Nelson D. R., and Zaylskie R. G. ( 1978 ) Insect hydrocarbons. Corroboration of structure by synthesis and mass spectrometry of mono- and dimethyl-alkanes. J. Chem. Ecol. 4, 27-39.

Pomonis J. G., Nelson D. R., and Fatland C. (1980) Insect hydrocarbons 2. Mass spectra of dimethylalkanes and the effect of the number of methylene units between methyl groups on fragmentation. J. Chem. Ecol. 6, 965-973.

Pomonis J. G., Hakk H., and Fatland C. L. (1989) Synthetic methyland dimethylalkanes. Kovats indices, $\left[{ }^{13} \mathrm{C}\right] \mathrm{NMR}$ and mass spectra of some methylpentacosanes and $2, X$-dimethyl-heptacosanes. $J$. Chem. Ecol. 15, 2319-2333.

Purser B. H. (1983) Sedimentation et diagenese des carbonates neritiques recents, Tome 2 . Edition Technip.

Robinson N. and Eglinton G. (1990) Lipid chemistry in Icelandic hot spring microbial mats. Org. Geochem. 15, 3, 291-298.

Robinson R. A. and Kaesler R. L. (1987) Phylum Arthropoda, part 1. In Fossil Invertebrates (ed. R. S. Boardman et al.), pp. 205269. Blackwell.

Robson J. N. and Rowland S. J. ( 1988) Biodegradation of highly branched isoprenoid hydrocarbons: A possible explanation of sedimentary abundance. In Advances in Organic Geochemistry 1987 (ed. L. Mattavelli and L. Novelli); Org. Geochem. 13, 691-695.

Shiea J., Brassell S. C., and Ward D. M. ( 1990 ) Mid-chain branched mono- and dimethyl alkanes in ancient sediments. Org. Geochem. $15,223-231$.

Shiea J., Brassell S. C., and Ward D. M. (1991) Comparative analysis of extractable lipids in hot spring microbial mats and their component photosynthetic bacteria. Org. Geochem. 17, 309-319.

Summons R. E. ( 1987) Branched alkanes from ancient and modern sediments: Isomer discrimination by GC/MS with multiple reaction monitoring. Org. Geochem. 11, 281-289.

Summons R. E., Brassell S. C., Eglinton G., Evans E., Horodysky R. J., Robinson N., and Ward D. M. (1988a) Distinctive hydrocarbon biomarkers from fossiliferous sediment of the Late Proterozoic Walcott Member, Chuar Group, Grand Canyon, Arizona. Geochim. Cosmochim. Acta 52, 2625-2637.

Summons R. E., Powell T. G., and Boreham C. J. ( 1988b) Petroleum geology and geochemistry of the Middle Proterozoic McArthur Bassin, Northern Australia: Ill. Composition of extractable hydrocarbons. Geochim. Cosmochim. Acta 52, 1747-1763.

Wiley G. A., Hershkowitz R. L., Rein B. M., and Chung B. C. ( 1964 ) Conversion of dodecanol- 2 by tertiary phosphine dibromide in DMF. J. Amer. Chem. Soc. 86, 964-965.

Yon D. A., Maxwell J. R., and Ryback G. (1982) 2,6,10-Trimethyl7-(3-methylbutyl)dodecane, a novel sedimentary biological marker compound. Tetrahedron Lett. 23, 2143-2146. 